Cochrane Database of Systematic Reviews

\title{
Nerve-sparing radical hysterectomy compared to standard radical hysterectomy for women with early stage cervical cancer (stage la2 to Ila) (Review)
}

Kietpeerakool C, Aue-aungkul A, Galaal K, Ngamjarus C, Lumbiganon P

Kietpeerakool C, Aue-aungkul A, Galaal K, Ngamjarus C, Lumbiganon P.

Nerve-sparing radical hysterectomy compared to standard radical hysterectomy for women with early stage cervical cancer (stage la2 to lla).

Cochrane Database of Systematic Reviews 2019, Issue 2. Art. No.: CD012828.

DOI: 10.1002/14651858.CD012828.pub2.

\section{www.cochranelibrary.com}


TABLE OF CONTENTS

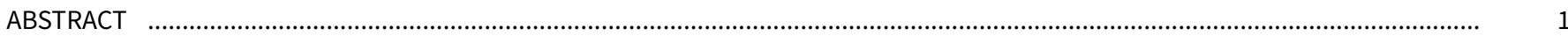

PLAIN LANGUAGE SUMMARY

SUMMARY OF FINDINGS

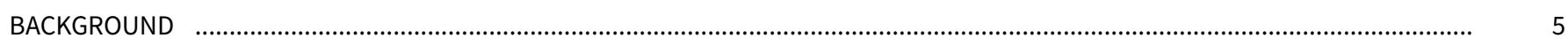

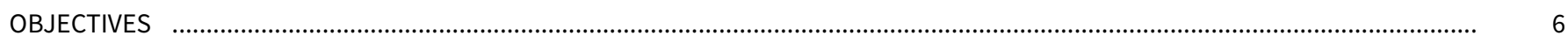

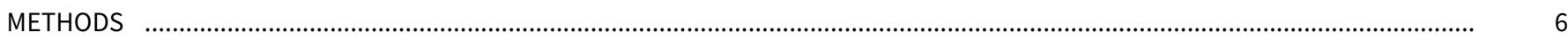

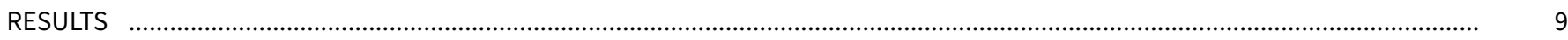

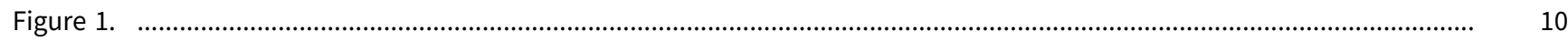

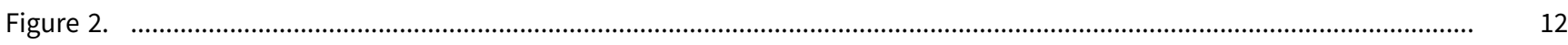

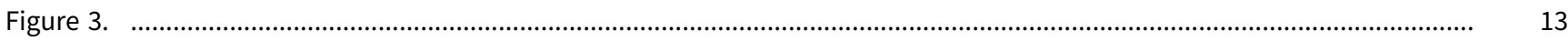

DISCUSSION

AUTHORS' CONCLUSIONS

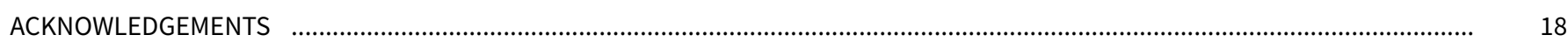

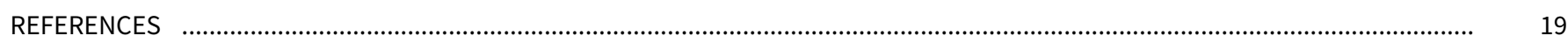

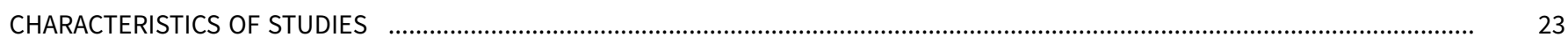

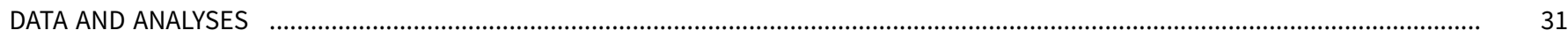

Analysis 1.1. Comparison 1 Postvoid residual volume of urine measured after operation, Outcome 1 Time to postvoid residual 32

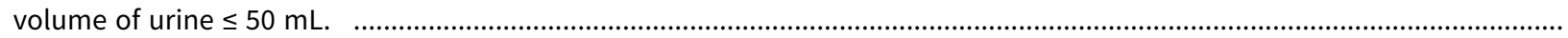

Analysis 1.2. Comparison 1 Postvoid residual volume of urine measured after operation, Outcome 2 Time to postvoid residual volume of urine $\leq 100 \mathrm{~mL}$.

Analysis 1.3. Comparison 1 Postvoid residual volume of urine measured after operation, Outcome 3 Postvoid residual volume of urine at 1 month after operation.

Analysis 1.4. Comparison 1 Postvoid residual volume of urine measured after operation, Outcome 4 Postvoid residual volume of urine at 3 months after operation.

Analysis 1.5. Comparison 1 Postvoid residual volume of urine measured after operation, Outcome 5 Postvoid residual volume of urine at 12 months after operation.

Analysis 2.1. Comparison 2 Adverse events (excluding bladder dysfunction), Outcome 1 Perioperative complication. .............

Analysis 3.1. Comparison 3 Subjective urinary symptoms, Outcome 1 Subjective urinary symptoms at 1 months after operation.

Analysis 3.2. Comparison 3 Subjective urinary symptoms, Outcome 2 Subjective urinary symptoms at 3 months after operation.

Analysis 3.3. Comparison 3 Subjective urinary symptoms, Outcome 3 Subjective urinary symptoms at 6 months after operation.

Analysis 4.1. Comparison 4 Disease-free survival, Outcome 1 Disease-free survival.

Analysis 5.1. Comparison 5 Cancer recurrence, Outcome 1 Rate of cancer recurrence.

Analysis 6.1. Comparison 6 Maximal urethral closure pressure $(\mathrm{cmH} 2 \mathrm{O})$, Outcome 1 Maximal urethral closure pressure $(\mathrm{cmH} 2 \mathrm{O})$ by urodynamic study at 1 month after operation.

Analysis 6.2. Comparison 6 Maximal urethral closure pressure $(\mathrm{cmH} 2 \mathrm{O})$, Outcome 2 Maximal urethral closure pressure $(\mathrm{cmH} 2 \mathrm{O})$ by urodynamic study at 6-12 months after operation.

Analysis 7.1. Comparison 7 Flow rate ( $\mathrm{mL}$ per second), Outcome 1 Maximum flow rate ( $\mathrm{mL}$ per second) at 1 month after operation.

Analysis 7.2. Comparison 7 Flow rate ( $\mathrm{mL}$ per second), Outcome 2 Maximum flow rate ( $\mathrm{mL}$ per second) at 6-12 months after operation.

Analysis 8.1. Comparison 8 Detrusor pressure $(\mathrm{cmH} 2 \mathrm{O})$, Outcome 1 Detrusor pressure at maximum flow at 1 month after operation.

Analysis 8.2. Comparison 8 Detrusor pressure $(\mathrm{cmH} 2 \mathrm{O})$, Outcome 2 Detrusor pressure at maximum flow at 6-12 months after operation.

Analysis 9.1. Comparison 9 Operative time (minutes), Outcome 1 Operative time ( $\mathrm{min})$.

Analysis 10.1. Comparison 10 Estimated blood loss $(\mathrm{mL})$, Outcome 1 Estimated blood loss $(\mathrm{mL})$. ADDITIONAL TABLES

APPENDICES 
[Intervention Review]

\section{Nerve-sparing radical hysterectomy compared to standard radical hysterectomy for women with early stage cervical cancer (stage la2 to} Ila)

Chumnan Kietpeerakool ${ }^{1}$, Apiwat Aue-aungkul ${ }^{1}$, Khadra Galaal ${ }^{2}$, Chetta Ngamjarus ${ }^{3}$, Pisake Lumbiganon ${ }^{1}$

1Department of Obstetrics and Gynaecology, Faculty of Medicine, Khon Kaen University, Khon Kaen, Thailand. ${ }^{2}$ Gynaecological Oncology, Princess Alexandra Wing, Royal Cornwall Hospital, Truro, UK. ${ }^{3}$ Department of Epidemiology and Biostatistics, Faculty of Public Health, Khon Kaen University, Khon Kaen, Thailand

Contact: Chumnan Kietpeerakool, Department of Obstetrics and Gynaecology, Faculty of Medicine, Khon Kaen University, 123 Mitraparb Road, Amphur Muang, Khon Kaen, 40002, Thailand. kiet_ji@hotmail.com.

Editorial group: Cochrane Gynaecological, Neuro-oncology and Orphan Cancer Group.

Publication status and date: New, published in Issue 2, 2019.

Citation: Kietpeerakool C, Aue-aungkul A, Galaal K, Ngamjarus C, Lumbiganon P. Nerve-sparing radical hysterectomy compared to standard radical hysterectomy for women with early stage cervical cancer (stage la2 to Ila). Cochrane Database of Systematic Reviews 2019, Issue 2. Art. No.: CD012828. DOI: 10.1002/14651858.CD012828.pub2.

Copyright ( 2019 The Cochrane Collaboration. Published by John Wiley \& Sons, Ltd.

\section{A B S T R A C T}

\section{Background}

Radical hysterectomy is one of the standard treatments for stage la2 to lla cervical cancer. Bladder dysfunction caused by disruption of the pelvic autonomic nerves is a common complication following standard radical hysterectomy and can affect quality of life significantly. Nerve-sparing radical hysterectomy is a modified radical hysterectomy, developed to permit resection of oncologically relevant tissues surrounding the cervical lesion, while preserving the pelvic autonomic nerves.

\section{Objectives}

To evaluate the benefits and harms of nerve-sparing radical hysterectomy in women with stage la2 to lla cervical cancer.

\section{Search methods}

We searched the Cochrane Central Register of Controlled Trials (CENTRAL; 2018, Issue 4), MEDLINE via Ovid (1946 to May week 2, 2018), and Embase via Ovid (1980 to 2018, week 21). We also checked registers of clinical trials, grey literature, reports of conferences, citation lists of included studies, and key textbooks for potentially relevant studies.

\section{Selection criteria}

We included randomised controlled trials (RCTs) evaluating the efficacy and safety of nerve-sparing radical hysterectomy compared to standard radical hysterectomy for women with early stage cervical cancer (stage la2 to lla).

\section{Data collection and analysis}

We applied standard Cochrane methodology for data collection and analysis. Two review authors independently selected potentially relevant RCTs, extracted data, evaluated risk of bias of the included studies, compared results and resolved disagreements by discussion or consultation with a third review author, and assessed the certainty of evidence.

\section{Main results}

We identified 1332 records as a result of the search (excluding duplicates). Of the 26 studies that potentially met the review criteria, we included four studies involving 205 women; most of the trials had unclear risks of bias. We identified one ongoing trial. 
The analysis of overall survival was not feasible, as there were no deaths reported among women allocated to standard radical hysterectomy. However, there were two deaths in among women allocated to the nerve-sparing technique. None of the included studies reported rates of intermittent self-catheterisation over one month following surgery. We could not analyse the relative effect of the two surgical techniques on quality of life due to inconsistent data reported. Nerve-sparing radical hysterectomy reduced postoperative bladder dysfunctions in terms of a shorter time to postvoid residual volume of urine $\leq 50 \mathrm{~mL}$ (mean difference (MD) -13.21 days; $95 \%$ confidence interval ( $\mathrm{Cl})-24.02$ to $-2.41 ; 111$ women; 2 studies; low-certainty evidence) and lower volume of postvoid residual urine measured one month following operation (MD -9.59 days; $95 \% \mathrm{Cl}-16.28$ to $-2.90 ; 58$ women; 2 study; low-certainty evidence). There were no clear differences in terms of perioperative complications (RR $0.55 ; 95 \% \mathrm{Cl} 0.24$ to $1.26 ; 180$ women; 3 studies; low-certainty evidence) and disease-free survival (HR 0.63; 95\% $\mathrm{Cl} 0.00$ to 106.95; 86 women; one study; very low-certainty evidence) between the comparison groups.

\section{Authors' conclusions}

Nerve-sparing radical hysterectomy may lessen the risk of postoperative bladder dysfunction compared to the standard technique, but the certainty of this evidence is low. The very low-certainty evidence for disease-free survival and lack of information for overall survival indicate that the oncological safety of nerve-sparing radical hysterectomy for women with early stage cervical cancer remains unclear. Further large, high-quality RCTs are required to determine, if clinically meaningful differences of survival exist between these two surgical treatments.

\section{PLAIN LANGUAGE SUMMARY}

\section{Nerve-sparing radical hysterectomy for early stage cervical cancer}

\section{The issue}

Radical hysterectomy is one of the standard treatments for early stage cervical cancer. In this operation, the uterus (womb), cervix, upper vagina and tissues surrounding the cervix and upper vagina are removed. Because of the extent of this operation, women may experience problems with urinating which impacts on quality of life.

\section{The aim of the review}

Nerve-sparing radical hysterectomy is a modified radical hysterectomy technique developed to preserve pelvic nerves in order to prevent bladder dysfunction. However, there is the potential that the operation may reduce survival and increase the chance of cancer recurring. We searched the scientific databases for articles published to May 2018 and included the studies in which women were randomly allocated to either standard operation or nerve-sparing operation.

\section{What are the main findings?}

We found four small studies that compared nerve-sparing radical hysterectomy versus standard radical hysterectomy. None of the included studies reported data on overall survival and rate of intermittent self-catheterisation (procedure in which patient periodically inserts a small tube (catheter) through the urethra into the bladder to empty it of urine) over one month following surgery. We could not assess the relative effect of these two operations on quality of life due to inconsistent data reported. Women undergoing nerve-sparing radical hysterectomy had better voiding (a technique of bladder training in which the woman is instructed to urinate according to predetermined schedules) functions following surgery than those undergoing standard radical hysterectomy. We found no evidence that women undergoing nerve-sparing radical hysterectomy were more likely to have adverse consequences of surgery or relapse of their cancer. The certainty of the evidence is therefore low or very low.

\section{What are the conclusions?}

Nerve-sparing radical hysterectomy may reduce the chance of bladder dysfunction compared to standard radical hysterectomy. However, the certainty of this evidence is low and further studies have the potential to better inform this outcome. We are very uncertain as to whether nerve-sparing radical hysterectomy is safe in terms of cancer survival outcomes. The evidence of cancer recurrence was of very low-certainty, there were no long term data available regarding risk of death from cancer or other causes. High-quality international studies involving many women would be needed to tell us whether nerve-sparing radical hysterectomy is beneficial in terms of survival for women with early stage cervical cancer, since risk of recurrence in this group are low. 


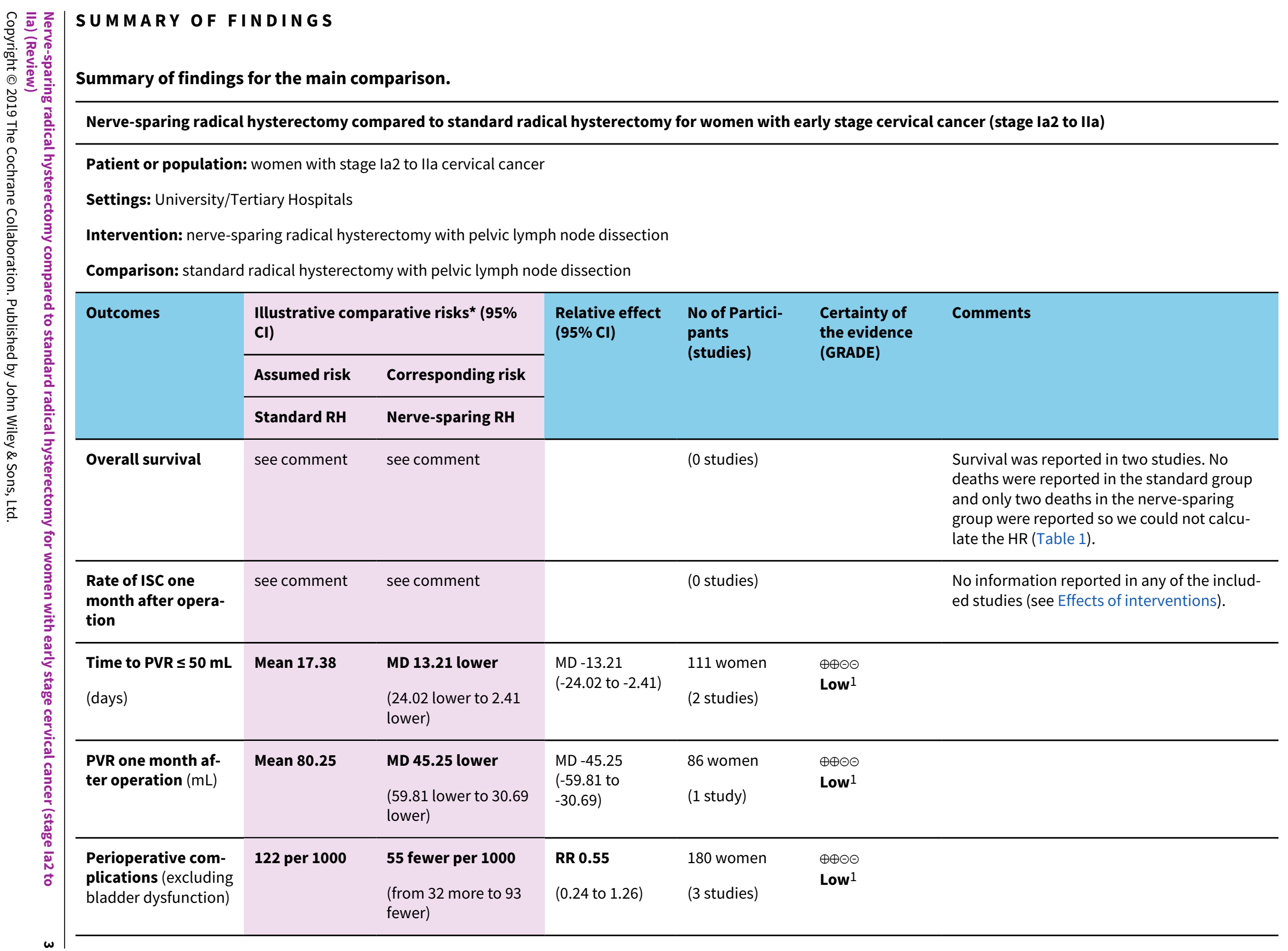




\begin{tabular}{|c|c|c|c|c|c|c|c|}
\hline 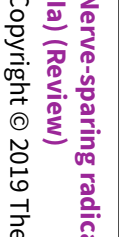 & $\begin{array}{l}\text { Disease-free sur- } \\
\text { vival } \\
\text { (median follow-up: } \\
101 \text { months; range } 13 \\
\text { to } 137 \text { months) }\end{array}$ & 50 per 1000 & $\begin{array}{l}19 \text { fewer per } 1000 \\
\text { (50 fewer to } 5,298 \\
\text { more) }\end{array}$ & $\begin{array}{l}\text { HR } \mathbf{0 . 6 3} \\
(0.00 \text { to } 106.95)\end{array}$ & $\begin{array}{l}86 \text { women } \\
\text { (1 study) }\end{array}$ & $\begin{array}{l}\oplus \ominus \ominus \ominus \\
\text { Very low } 2\end{array}$ & $\begin{array}{l}\text { Survival was reported in two studies. In one } \\
\text { study, however there had been only one case } \\
\text { with cancer recurrence so this precluded } \\
\text { analysis of HR (Table } 1 \text { ). }\end{array}$ \\
\hline 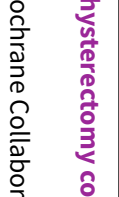 & Quality of life & see comment & see comment & & (0 studies) & & $\begin{array}{l}\text { One study reported quality of life but there } \\
\text { had been inconsistency between the state- } \\
\text { ment of the authors and reported data. So, } \\
\text { we did not perform any analyses for this out- } \\
\text { come (see Effects of interventions). }\end{array}$ \\
\hline
\end{tabular}

${ }^{\star}$ The basis for the assumed risk (e.g. the median control group risk across studies) is provided in footnotes. The corresponding risk (and its $95 \%$ confidence interval) is based on the assumed risk in the comparison group and the relative effect of the intervention (and its $95 \% \mathrm{Cl}$ ).

RH: radical hysterectomy; ISC: Intermittent self-catheterisation; PVR: Postvoid residual volume of urine

CI: Confidence interval; RR: Risk ratio; MD: Mean difference; HR: Hazard ratio

GRADE Working Group grades of evidence

High-certainty: Further research is very unlikely to change our confidence in the estimate of effect.

Moderate-certainty: Further research is likely to have an important impact on our confidence in the estimate of effect and may change the estimate.

Low-certainty: Further research is very likely to have an important impact on our confidence in the estimate of effect and is likely to change the estimate.

Very low-certainty: We are very uncertain about the estimate.

1 Unclear risk of selection/detection/performance biases and small sample size/non-normally distributed data (-2)

Unclear risk of selection/detection/performance biases, small number of sample size and reported events, and applying unadjusted HRs in the analyses (-3) 


\section{B A C K G R O U N D}

\section{Description of the condition}

Cervical cancer remains a major health burden, with an agestandardised incidence rate (ASR) of 14.0 per 100,000 person-years (Ferlay 2015). In 2012, there were an estimated 528,000 new cases worldwide (Ferlay 2015). Approximately $85 \%$ of the global burden and nine out of $10(87 \%)$ cervical cancer deaths occur in lowand/or middle-income countries (Ferlay 2015). This high rate of cervical cancer-related death in these countries is mainly due to deficiencies in surveillance systems (Parkin 2014). Treatment for cervical cancer depends on the clinical stage of the disease. Staging of cervical cancer (processes carried out to find out how far the cancer has spread) is based on clinical findings obtained from physical examination and diagnostic tests, which are used to assess the size of cervical mass, invasion into the tissues surrounding the cervix, and the spread to lymph nodes or distant organs (FIGO Committee 2014). The International Federation of Gynecology and Obstetrics (FIGO) staging system for cervical cancer is provided in Appendix 1 (FIGO Committee 2014).

A radical hysterectomy (also known as a Wertheim's hysterectomy) is performed to remove the uterus (womb), cervix, upper vagina and the parametria (tissues surrounding the cervix and upper vagina) (Marin 2014; Verleye 2009). Radical hysterectomy, in conjunction with bilateral pelvic lymphadenectomy (the surgical removal of the lymph nodes found in the pelvis), is the standard surgical treatment for FIGO stage la2-Ila cervical cancer, when preservation of fertility is not required or advisable (Verleye 2009), although more limited treatment, such as cone biopsy (removal of a cone shaped piece of tissue from the cervix) or simple hysterectomy, with lymph node dissection, is increasingly considered for small volume disease. Concurrent chemoradiation (combination of drug and radiotherapy given at the same time) is also acknowledged as a standard treatment option for women with early stage cervical cancer (Vale 2010). Decision-making is based on individual patient characteristics and preferences, as well as weighing up the surgical risks with the longer-term risks of chemoradiation.

Radical hysterectomy can be performed via laparotomy (open surgery), laparoscopic or robotic techniques (types of less invasive surgery). At present, there are three standard classification systems for radical hysterectomy (Marin 2014; Verleye 2009), including the Piver-Rutledge-Smith classification (Piver 1974), Querleu and Morrow classification (Querleu 2008), and the Gynecological Cancer Group of the European Organization for Research and Treatment of Cancer (GCG-EORTC) classification (Mota 2008) (See Appendix 2). See Cibula 2011; Marin 2014 and Querleu 2008 for detailed diagrams and figures demonstrating the differences in the types of hysterectomy.

Five-year survival rates of women undergoing radical hysterectomy for stage la2 to lla cervical cancer are over $80 \%$ (Hongladaromp 2014; Kim 2000; Mahawerawat 2013; Srisomboon 2011; Suprasert 2010). The procedure can, however, result in significant long-term complications (Laterza 2015; Manchana 2009; Suprasert 2010). Bladder dysfunction (problems with urinating), caused by the disruption of the pelvic autonomic nerves during resections of parametria and paracolpium (the tissues surrounding the vagina), can be a major, distressing complication and may occur in up to $70 \%$ of women following radical hysterectomy (Laterza
2015; Plotti 2011; Suprasert 2010). Early postoperative bladder dysfunction includes a significant reduction of maximal urethral closure pressure (MUCP), increased volume of postvoid residual urine (PVR), detrusor muscle under activity and diminished bladder sensation, which, in some cases, may require prolonged urethral catheterisation. Late postoperative bladder dysfunction involves a persistent reduction of MUCP, voiding with abdominal straining, high volume of PVR, detrusor muscle over-activity, and stress urinary incontinence (loss of urine caused by physical stress, e.g. sneezing or jumping) with estimates ranging from $8 \%$ to $47 \%$ (Katepratoom 2014; Laterza 2015).

\section{Description of the intervention}

The uterus, upper vagina, bladder and rectum receive innervation from both the sympathetic and parasympathetic supplies of the autonomic nervous system (a control system that acts largely unconsciously and regulates bodily functions). These nerves control smooth muscle function and pain sensation in viscera (internal organs). The sympathetic supply arises from the eleventh thoracic vertebra (T11) to the second lumbar vertebra (L2) nerve roots, which form a branching network called the superior hypogastric plexus (also referred to as the presacral nerve). The superior hypogastric plexus enters the pelvis, dividing into right and left hypogastric nerves. The pelvic splanchnic nerve is formed from parasympathetic fibres from S2-S4 nerve roots. The pelvic splanchnic nerve merges with the hypogastric nerve to form left and right inferior hypogastric plexuses, which travel via the uterosacral ligaments (tissues that connect between the posteriorlower part of the uterus to the anterior aspect of the sacrum) where they branch to supply the uterus and bladder (Fujii 2007; Huber 2015).

In terms of urinary function, the sympathetic nervous system relaxes the bladder muscle (detrusor muscle) to increase bladder capacity and constricts the internal urethral sphincter to inhibit the micturition (bladder voiding) reflex. The parasympathetic nervous system stimulates a series of contractions of the bladder muscle and relaxes the internal urethral sphincter (muscle that acts as a valve to control the exit of urine from the bladder), resulting in voluntary urination (Laterza 2015).

Nerve-sparing radical hysterectomy is a modified radical hysterectomy, developed to permit surgical removal (resection) of oncologically relevant tissues surrounding the cervical lesion, while preserving pelvic autonomic nerves (Charoenkwan 2010; Fujii 2008; Kato 2003). During nerve-sparing radical hysterectomy, parametrial dissection is carried out under directed visualisation of the adjacent pelvic autonomic nerves. Fibres of the hypogastric nerve can be identified in the mesoureter (tissues surrounding the ureter), approximately $2 \mathrm{~cm}$ to $3 \mathrm{~cm}$ beneath the ureter (tubes that carry urine from kidneys to the bladder). To minimise the risk of accidental transection (severing), the hypogastric nerve is partly dissected away from the level of resection of the posterior parametrium. During resection of the lateral parametrium, the inferior hypogastric plexus is directly visualised, partly dissected and separated to avoid disruption during resection. The vesical branch of inferior hypogastric plexus can be identified by following the course of the inferior hypogastric plexus from the uterosacral ligaments and is separated from the blood vessels of the tissue surrounding the vagina during resection of the anterior parametrium (Charoenkwan 2006; Charoenkwan 2010; Fujii 2007; Fujii 2008).

Nerve-sparing radical hysterectomy compared to standard radical hysterectomy for women with early stage cervical cancer (stage la2 to

IIa) (Review)

Copyright (c) 2019 The Cochrane Collaboration. Published by John Wiley \& Sons, Ltd. 
Previous studies proposed that nerve-sparing radical hysterectomy may be feasible without compromising the extent of resection and the rate of cancer recurrence when compared to the standard techniques of radical hysterectomy (Charoenkwan 2006; Kim 2015a; Xue 2016). A factor predicting the likelihood of the success of nerve-sparing radical hysterectomy is the FIGO stage of the disease. Women with stage Ib1 cervical cancer are more likely to have successful preservation of autonomic nerves during laparoscopic nerve-sparing radical hysterectomy than those with a higher stage of disease (stage Ib2 to lla) (Kim 2015a).

\section{How the intervention might work}

The extent of potential injury to pelvic autonomic nerves is associated with the extent of the operation (Butler-Manuel 2000; Ercoli 2003). The surgical steps of radical hysterectomy that potentially damage the pelvic autonomic nerves are the resection of parametrial tissues, particularly posterior and anterior parametria (Ercoli 2003). Previous quantitative immunocytochemistry studies (postoperative examination of tissue removed during surgery using antibodies to highlight nerve fibres when viewed under a microscope) indicated that the presence of nerve trunks (the main stem of a nerve), autonomic ganglia (nerve connection hubs), and free nerve fibres within the parametrial tissues, which were transected during conventional radical hysterectomy (Butler-Manuel 2000; Ercoli 2003; Maas 2005; Mantzaris 2008). In addition, when a more careful approach is used during resection of the parametria, through identification and isolation of the adjacent pelvic autonomic nerves, significantly fewer autonomic nerves are disrupted iatrogenically (inadvertently) during nerve-sparing radical hysterectomy than in conventional radical hysterectomy (Maas 2005; Mantzaris 2008). This results in a substantial reduction in nerve disruption and may lower the risk of developing bladder dysfunction after radical hysterectomy (Charoenkwan 2010; Fujii 2007; Tseng 2012).

\section{Why it is important to do this review}

Although the survival outcomes of women undergoing standard radical hysterectomy with pelvic lymphadenectomy for stage la2 to Ila cervical cancer are generally good, bladder dysfunction following standard radical hysterectomy can affect quality of life significantly (Ceccaroni 2012; Wu 2010. Nerve-sparing radical hysterectomy may offer improved quality of life. However, there is the potential that a nerve-sparing approach may compromise oncological outcomes and increase the risk of disease recurrence. We aimed to assess the benefits and harms of this approach in order to inform women and their surgeons about whether a more refined surgical approach is warranted, or whether a more traditional radical resection is to be recommended.

\section{OB JECTIVES}

To evaluate the benefits and harms of nerve-sparing radical hysterectomy in women with stage la2 to Ila cervical cancer.

\section{METHODS}

\section{Criteria for considering studies for this review}

\section{Types of studies}

\section{Types of participants}

Women aged 18 years or older undergoing radical hysterectomy (Piver class III, Querleu and Morrow type C, or European Organization for Research and Treatment of Cancer (GCG-EORTC) type III) for stage la2 to Ila cervical cancer. Appendix 1 and Appendix 2 display the details of the FIGO staging classification of cervical cancer, and the classifications of radical hysterectomy, respectively. If studies include other stages of cervical cancer, we planned to contact trial authors to retrieve data related to the women with stage la2 to lla cervical cancer only.

\section{Types of interventions}

Randomised controlled trials comparing nerve-sparing radical hysterectomy with pelvic lymphadenectomy versus standard radical hysterectomy with pelvic lymphadenectomy for cervical cancer stage la2 to lla irrespective of the types of surgical approach (i.e. laparotomy, laparoscopy or other minimally invasive surgery). See Description of the intervention for details of the differences between nerve-sparing radical hysterectomy and standard radical hysterectomy.

\section{Types of outcome measures}

\section{Primary outcomes}

- Overall survival: survival until death from all causes. Survival assessed from the time when women were enrolled in the study.

- Rate of intermittent self-catheterisation (ISC) at one month after the operation.

- Quality of life: assessed using a scale that has been validated through reporting of norms in a peer-reviewed publication, i.e. EORTC QLQ-CX24 cervical cancer-specific quality of life questionnaire (Greimel 2006).

\section{Secondary outcomes}

- Time to postvoid residual volume of urine $\leq 50 \mathrm{~mL}$ after operation (days) (amounts of urine measured by clean intermittent catheterisation after the patient feels as though bladder is empty).

- Postvoid residual urine volume (PVR) of urine at one month, three months, six months, and 12 months after operation $(\mathrm{mL})$.

- Adverse events (excluding bladder dysfunction): we planned to categorise the severity of the following adverse events according to the Common Terminology Criteria for Adverse Events (CTCAE 2010): febrile morbidity; surgical site infections; genitourinary complications (e.g. fistula, hydronephrosis, vaginal stenosis); gastrointestinal complications (e.g. fistula, constipation); lymphovascular complications (e.g. lymphocyst, lymphoedema, thrombosis, embolism); direct surgical morbidity (e.g. injury to bladder, ureter, small bowel or colon); reoperation (an operation to correct a condition not corrected by a previous operation or to correct the complications of a previous operation); readmission (a hospitalisation that occurs within 30 days after discharge from hospital); blood component transfusion (the transfer of blood or blood components from one person (the donor) into the bloodstream of another person (the recipient).

- Subjective urinary symptoms: using a standard questionnaire, i.e. International Prostate Symptom Score (IPSS) (Barry 1992)

Randomised controlled trials (RCTs).

Nerve-sparing radical hysterectomy compared to standard radical hysterectomy for women with early stage cervical cancer (stage la2 to

Ila) (Review)

Copyright (c) 2019 The Cochrane Collaboration. Published by John Wiley \& Sons, Ltd. 
- Disease-free survival (DFS): survival until the appearance of a new lesion of disease. Survival will be assessed from the time when women are enrolled in the study.

- Rate of cancer recurrence: we will classify recurrences as locoregional or distant.

- Rate of urinary tract infection during the month after operation diagnosed by cultivation of urine.

- Maximal urethral closure pressure (MUCP) from urodynamic measurements $\left(\mathrm{cmH}_{2} \mathrm{O}\right)$.

- Maximum flow rate ( $\mathrm{mL}$ per second) and number of women with low maximum flow rate $(<15 \mathrm{~mL}$ per second) obtained urodynamic measures.

- Detrusor pressure at maximum flow and number of women with low detrusor pressure at maximum flow $\left(<25 \mathrm{~cm} \mathrm{H}_{2} \mathrm{O}\right)$.

- Sexual dysfunction: using a validated scale, i.e. Sexual functionVaginal change Questionnaire (SVQ) (Jensen 2004).

- Cost-effectiveness: using a validated scale, i.e. European Society for Medical Oncology Magnitude of Clinical Benefit Scale (ESMOMCBS) (Cherny 2015).

- Operative time (minutes).

- Estimated blood loss ( $\mathrm{mL})$

See Summary of findings for the main comparison which reports the following outcomes listed in order of priority.

- Overall survival

- Rate of ISC one month after operation;

- Time to postvoid residual volume of urine $\leq 50 \mathrm{~mL}$ after operation;

- Postvoid residual volume of urine one month after operation;

- Rate of adverse event excluding bladder dysfunction;

- Disease-free survival (DFS); and

- Quality of life.

\section{Search methods for identification of studies}

We included RCTs, irrespective of the language of publication, publication status or sample size.

\section{Electronic searches}

We searched the following electronic databases:

- the Cochrane Central Register of Controlled Trials (CENTRAL; 2018, Issue 4), in the Cochrane Library;

- MEDLINE via Ovid (1946 to May week 2, 2018);

- Embase via Ovid (1980 to 1980 to 2018, week 21).

Appendix 3, Appendix 4, and Appendix 5 display the search strategies for CENTRAL, MEDLINE, and Embase. All relevant articles were identified on PubMed and we made a further search for newly published articles using the 'related articles' feature.

\section{Searching other resources}

\section{Ongoing trials and grey literature}

We searched the World Health Organization's International Clinical Trials Registry Platform (www.who.int/ictrp/en) and ClinicalTrials.gov to identify any ongoing trials. Had we identified ongoing trials that had not been published, we planned to approach the principal investigators and major co-operative groups active in this area, to ask for relevant data. We searched the following databases for grey literature: Open Grey (www.opengrey.eu) and Index to Theses (ProQuest Dissertations \& Theses: UK \& Ireland).

\section{Handsearching}

We handsearched the citation lists of included studies, key textbooks and previous systematic reviews. We planned to contact experts in the field to identify further reports of trials. We also handsearched the reports of conferences from the following sources (from the year when electronic conference proceedings became available to current):

- Annual Meeting of the American Society of Gynecologic Oncology;

- Annual Meeting of the European Society of Medical Oncology;

- Annual Meeting of the American Society of Clinical Oncology;

- Annual Meeting of the British Gynaecological Cancer Society;

- Biennial Meeting of the Asian Society of Gynecologic Oncology;

- Biennial Meeting of the Asia and Oceania Federation of Obstetrics and Gynaecology;

- Biennial Meeting of the European Society of Gynaecological Oncology; and

- Biennial Meeting of the International Gynecologic Cancer Society.

\section{Data collection and analysis}

\section{Selection of studies}

We downloaded all titles and abstracts retrieved by electronic searching to a reference management database (EndNote). After duplicates were removed, we transferred these data to Covidence (www.covidence.org). We excluded those studies that clearly did not meet the inclusion criteria and we obtained copies of the full text of potentially relevant references. Independently, two review authors (CK and AA) assessed the eligibility of the retrieved reports/ publications. We resolved any disagreement through discussion or, if required, we consulted a third person (KG or PL). We identified and excluded duplicates and collated multiple reports of the same study. We used the details regarding the selection process in Covidence to complete a PRISMA flow diagram and 'Characteristics of excluded studies' table (Liberati 2009).

\section{Data extraction and management}

Two review authors ( $C K$ and $A A$ ) independently extracted study characteristics and outcome data from included studies. We noted when outcome data were not reported in a usable way in the Characteristics of included studies table. We intended to resolve disagreements by consensus or by involving a third person (KG or $\mathrm{PL})$.

For included studies, we extracted the following data.

- Author, year of publication and journal citation (including language)

- Country

- Setting

- Inclusion and exclusion criteria

- Study design and methodology

- Study population and disease characteristics

Nerve-sparing radical hysterectomy compared to standard radical hysterectomy for women with early stage cervical cancer (stage la2 to

Ila) (Review)

Copyright (c) 2019 The Cochrane Collaboration. Published by John Wiley \& Sons, Ltd. 
- Total number enrolled

- Participant characteristics

- Age

- Co-morbidities

- Other baseline characteristics

- Surgical technique (laparotomy, laparoscopy or roboticassisted procedure)

- Estimated blood loss ( $\mathrm{mL})$

- Stage of cervical cancer

- Histopathological subtype of cervical cancer

- Tumour size (largest tumour diameter)

- Lymphadenectomy details including technique (sampling versus complete dissection) and status of lymph nodes (negative or positive for metastasis)

- Radicality of the operation

- Operative time (minutes)

- Postoperative adjuvant treatment received and indication

- Intervention details

- Nerve-sparing radical hysterectomy

- Comparison

- Conventional radical hysterectomy

- Risk of bias in study (see below)

- Duration of follow-up

- Outcomes: for each outcome, we extracted the outcome definition and unit of measurement (if relevant). For adjusted estimates, we recorded variables adjusted for in analyses.

- Results: we extracted the number of participants allocated to each intervention group, the total number analysed for each outcome and the missing participants.

- Notes: funding for trial and notable conflicts of interest of trial authors.

We extracted results as follows.

- For time-to-event data (survival outcomes and time to postvoid residual urine (PVR) $\leq 50 \mathrm{~mL}$ after operation), we extracted the $\log$ of the hazard ratio $(\log (\mathrm{HR}))$ and its standard error from trial reports. If these were not reported, we estimated the log (HR) and its standard error using the methods of Parmar 1998.

- For dichotomous outcomes (e.g. adverse events and urinary tract infection), we extracted the number of women in each treatment arm who experienced the outcome of interest and the number of women assessed at endpoint, in order to estimate a risk ratio $(\mathrm{RR})$

- For continuous outcomes (e.g. time to PVR $\leq 50 \mathrm{~mL}$ after operation, volume of PVR and quality of life measures), we extracted the final value and standard deviation (SD) of the outcome and the number of women assessed at endpoint in each treatment arm at the end of follow-up, in order to estimate the mean difference (MD) between treatment arms (if trials measured outcomes on the same scale) or standardised mean difference (SMF) (if trials measured outcomes on different scales) between treatment arms and its standard error. If continuous outcomes were expressed as median and range, we contacted the study author to obtain sample mean and SD. If this was not possible, we converted these data using the formula, as suggested by Wan 2014.
Where possible, we intended to extract data according to an intention-to-treat analysis, in which participants are analysed in the groups to which they were assigned.

\section{Assessment of risk of bias in included studies}

We assessed and reported on the methodological quality and risk of bias of included studies in accordance with the Cochrane Handbook for Systematic Reviews of Interventions (Higgins 2011), which recommends the explicit reporting of the following individual issues for RCTs.

- Selection bias: random sequence generation and allocation concealment

- Performance bias: blinding of participants and personnel (outcome assessors)

- Detection bias: blinding of outcome assessment

- Attrition bias: incomplete outcome data (i.e. incomplete followup outcomes and treatment-related complications)

- Reporting bias: selective reporting of outcomes

- Other potential bias

Two review authors (CK and $A A$ ) applied the Cochrane 'Risk of bias' tool independently and resolved differences by discussion or by appeal to a third review author (KG or PL). We judged each item as being at high, low or unclear risk of bias as set out in the criteria displayed in Appendix 6 (Higgins 2011). We provided a quote from the study report or a statement (or both) as justification for the judgement for each item in the 'Risk of bias' table. We summarised the results in both a 'Risk of bias' graph and a 'Risk of bias' summary. When interpreting treatment effects and metaanalyses, we took into account the risk of bias for the studies that contributed to that outcome. Where information on risk of bias relates to unpublished data, or correspondence with trial authors, we recorded this in the table.

\section{Measures of treatment effect}

We used the following measures of the effect of treatment.

- For time-to-event outcomes (DFS), we analysed data using hazard ratios (HR) with 95\% confidence intervals (Cl).

- For dichotomous outcomes (adverse events, cancer recurrence) we analysed data on the basis of the number of events and number of people assessed in the intervention and comparison groups. We used these to calculate the RR and $95 \% \mathrm{Cl}$.

- For continuous outcomes (volume of PVR, subjective urinary, MUCP, flow rate, detrusor pressure, operative time, and estimated blood loss), we analysed data based on the mean, standard deviation (SD) and number of people assessed for both the intervention and comparison groups to calculate the MD between treatment arms with a $95 \% \mathrm{Cl}$. If the MD was reported without individual group data, we intended to use this to report the study results. If more than one study measured the same outcome using different tools, we calculated the standardised mean difference (SMD) and $95 \% \mathrm{Cl}$ using the inverse variance method.

\section{Unit of analysis issues}

The units of analysis are the participants receiving interventions of interest. A study with multiple intervention groups is not applicable for this review, as we compared the two interventions,

Nerve-sparing radical hysterectomy compared to standard radical hysterectomy for women with early stage cervical cancer (stage la2 to 
namely nerve-sparing radical hysterectomy versus standard radical hysterectomy.

\section{Dealing with missing data}

We did not impute missing outcome data for any of the outcomes.

\section{Assessment of heterogeneity}

We assessed clinical heterogeneity by visual inspection of the forest plots. Also, we assessed statistical heterogeneity in each metaanalysis using the $\mathrm{I}^{2}$ statistic and $\mathrm{Chi}^{2}$ test (Deeks 2001; Higgins 2011). We performed subgroup analysis to investigate the potential heterogeneity of the included studies, if feasible. If there was evidence of substantial clinical and methodological heterogeneity across the included studies, we applied a narrative review approach to data synthesis.

\section{Assessment of reporting biases}

We were unable to assess reporting bias, as only four studies met our inclusion criteria.

\section{Data synthesis}

We carried out statistical analysis using Cochrane Review Manager 5 software (Review Manager 2014). We applied the randomeffects model with inverse variance weighting for all meta-analyses (DeSimonian 1986).

- For time-to-event data, we calculated pooled HRs using the generic inverse variance method.

- For any dichotomous outcomes, we computed the RR for each study and then pooled these.

- For continuous outcomes, we pooled the MD between the treatment arms, if all trials measured the outcome on the same scale; otherwise we pooled SMDs.

\section{Main outcomes of 'Summary of findings' table for assessing the certainty of the evidence}

We have prepared a Summary of findings for the main comparison to summarise the results of the meta-analysis based on the methods described in Chapter 11 of the Cochrane Handbook for Systematic Reviews of Interventions (Schünemann 2011).

We presented the results of meta-analyses and overall certainty of the evidence for seven main outcomes as outlined in Types of outcome measures according to the Grading of Recommendations Assessment, Development and Evaluation (GRADE) approach, which take into account issues not only related to internal validity (risk of bias, inconsistency, imprecision, publication bias), but also to external validity such as directness of results (Langendam 2013). We created a 'Summary of findings' table using GRADEpro GDT (www.gradepro.org). We downgraded the evidence from high certainty by one level for each serious limitation, or by two levels for any very serious limitation. The GRADE levels of evidence can be interpreted as shown below.

- High certainty: the true effect lies close to that of the estimate of the effect.

- Moderate certainty: the true effect is likely to be close to the estimate of the effect, but there is a possibility that it is substantially different.

- Low certainty: the true effect may be substantially different from the estimate of the effect.

- Very low certainty: the true effect is likely to be substantially different from the estimate of effect.

\section{Subgroup analysis and investigation of heterogeneity}

As only four studies assessing 205 women, met our inclusion criteria, subgroup analyses according to stage of the disease (la2-lb1 versus Ib2 or higher stages), and degree of lymph node dissection (pelvic versus pelvic and para-aortic) as mentioned in the review protocol were not feasible. However, we considered factors in the interpretation of review findings. In future updates, we will perform subgroup analysis according to these factors, if feasible.

\section{Sensitivity analysis}

We performed no sensitivity analyses, as all data were obtained from published RCTs that contained only women with cervical cancer stage la2 to Ila and all included RCTs were at unclear risk of bias for allocation concealment. In future updates, if statistical heterogeneity is detected and there is a sufficient number of included studies, we will perform sensitivity analyses to determine the possible contribution of other clinical or methodological differences between the trials, specifically:

- repeating the analysis excluding any unpublished studies:

- repeating the analysis excluding RCTs judged to be at high or unclear risk of bias for allocation concealment;

- repeating the analysis excluding RCTs that contained women with cervical cancer other than stage la2 to lla.

\section{RESULTS}

\section{Description of studies}

See Figure 1 for the PRISMA flow of study selection. 
Figure 1. Study flow diagram.

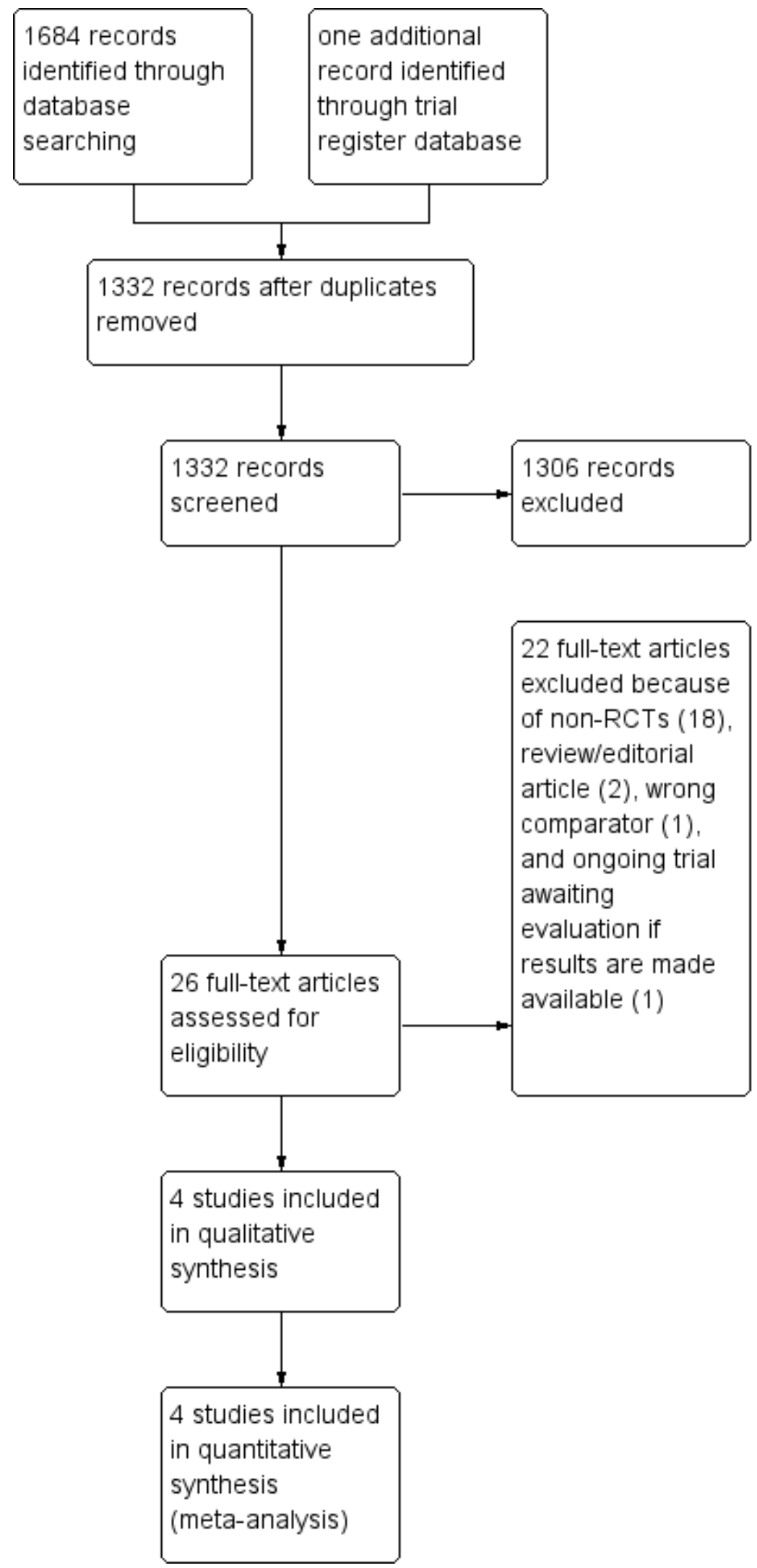

Nerve-sparing radical hysterectomy compared to standard radical hysterectomy for women with early stage cervical cancer (stage la2 to 


\section{Results of the search}

We ran a broad search in May 2018, MEDLINE search retrieved 711 studies. Searches of Embase and CENTRAL identified 921 studies and 52 studies, respectively. Searching trial register databases identified one ongoing study. After de-duplication, we screened titles and abstracts of 1332 references and excluded 1306 that obviously did not meet the review inclusion criteria. Of the 26 studies that potentially met our inclusion criteria, we excluded 21 references after reviewing the full-text and added on reference to Ongoing studies, leaving four studies assessing a total of 205 for quantitative synthesis. Searches of the grey literature, conference proceedings, and citation lists of included studies revealed no potentially eligible studies.

\section{Included studies}

\section{See Characteristics of included studies}

\section{Participants}

Chen 2012 recruited 25 women with FIGO stage Ib1 to lla cervical cancer (nine women with Ib1 stage disease; six with Ib2; 10 with Ila) who received neither neoadjuvant treatment and had no clinical bladder dysfunction. Thirteen participants (four women with Ib1stage disease; four with Ib2, and five with Ila) and 12 participants (five women with Ib1 stage disease; two with Ib2; five with Ila) were randomly assigned to undergo open nerve-sparing radical hysterectomy and standard open radical hysterectomy, respectively.

Chen 2014 randomised 65 women with FIGO stage la2 to lla cervical cancer (five women with la2 stage disease; 20 with Ib1; 10 with Ib2; 25 with Ila; and five with missing data on stage of cancer) to undergo laparoscopic nerve-sparing radical hysterectomy $(\mathrm{N}=30)$ or standard laparoscopic radical hysterectomy $(\mathrm{N}=35)$.

Roh 2015 randomised 92 women with FIGO stage Ib1 to lla cervical cancer to undergo nerve-sparing radical hysterectomy $(\mathrm{N}=48)$ or standard radical hysterectomy $(\mathrm{N}=44)$. However, only participants with a follow-up duration of more than one year after surgery were included in the final analyses (40 in open standard radical hysterectomy and 46 in open nerve-sparing radical hysterectomy). None of the participants had clinical urinary dysfunction before the operation.

Wu 2010 recruited 31 women with FIGO stage Ib1 to Ila cervical cancer who had no abnormal bladder function before the operation confirmed by urodynamic study. However, only 29 participants completed the study and were included in the analysis. Fifteen participants (12 women with Ib1 stage disease; two with Ib2; and one with Ila), and 14 participants (10 women with Ib1stage disease and four with Ila) were randomly assigned to undergo open nerve-sparing radical hysterectomy and open standard radical hysterectomy, respectively.

\section{Interventions}

The intervention in Chen 2012; Roh 2015; and Wu 2010 was class III (PIVER III) nerve-sparing radical hysterectomy with bilateral pelvic lymphadenectomy. The comparator was standard class III radical hysterectomy with bilateral pelvic lymphadenectomy. All operations in Chen 2012; Roh 2015; and Wu 2010 were performed via laparotomy (Chen 2012; Roh 2015; Wu 2010). In Chen 2014, operations were conducted via laparoscopy.

\section{Outcomes reported}

Chen 2012 reported the amount of removed nerve bundles and vessels, operative time, blood loss, and postoperative bladder and bowel functions including time to postvoid residual urinary volume $(P V R) \leq 50 \mathrm{~mL}$, time to first flatus and defecation, and status at last follow-up.

Chen 2014 reported blood loss, operative time, perioperative complications, bladder functions (duration of the postoperative catheterisation, maximum flow rate (MFR), maximum detrusor pressure (MDP)) assessed by urodynamic study performed at six to 12 months, intestinal functions, urinary symptoms, and quality of sexual life. The authors evaluated intestinal functions, urinary symptoms, and quality of sexual life 12 months following the operation. However, the authors did not report the number of participants assessed for bladder function assessment and quality of sexual life. We contacted the authors via their published contact details to ask for additional information, but none have been forthcoming.

Roh 2015 reported bladder function recovery including time to PVR $<50 \mathrm{mlLand}$ bladder function (PVR, maximal urethral closure pressure (MUCP), MFR, average flow rate (AFR), bladder compliance, and detrusor pressure at maximum flow) assessed by urodynamic study performed one, three and 12 months following the operation; and subjective urinary symptoms using International Prostate Symptom Score (IPPS); disease-free survival (DFS); and overall survival.

Wu 2010 reported postoperative complications, operative time, amount of blood loss, bladder function recovery including time to PVR $<100 \mathrm{~mL}$ and postoperative bladder function (PVR, MUCP, MFR, AFR, bladder compliance, and stress incontinence), and quality of life.

\section{Excluded studies}

After obtaining the full-text articles, we excluded 21 references and added on reference to Ongoing studies for the following reasons.

- Eighteen references were non-RCTs in which results were compared between women who underwent nerve-sparing radical hysterectomy and those who did not (Barbic 2012; Bogani 2014; Ceccaroni 2012; Charoenkwan 2010; Cibula 2010; Ditto 2009; Hockel 2000; Kanao 2014; Kim 2017; Querleu 2002; Raspagliesi 2006; Raspagliesi 2017; Shi 2016; Skret-Magierlo 2010; Su 2017; Todo 2006; Tseng 2012; Yang 2016).

- One RCT compared type II versus type III hysterectomy for cervical cancer, which is not a comparator of interest in this review (Milani 1991).

- One reference was a review article describing the surgical techniques for parametrial dissection during laparoscopic nerve-sparing radical hysterectomy (Ceccaroni 2010).

- One reference was an editorial article (Sakuragi 2015).

- One reference was an ongoing trial awaiting evaluation once the results are made available (Gaballa 2015).

For further details, see the Characteristics of excluded studies and Characteristics of ongoing studies tables.

Nerve-sparing radical hysterectomy compared to standard radical hysterectomy for women with early stage cervical cancer (stage la2 to

Ila) (Review)

Copyright (c) 2019 The Cochrane Collaboration. Published by John Wiley \& Sons, Ltd. 


\section{Risk of bias in included studies}

For further details on risk of bias in all included studies, see

Characteristics of included studies table; Figure 2; and Figure 3.

Figure 2. 'Risk of bias' graph: review authors' judgements about each risk of bias item presented as percentages across all included studies.

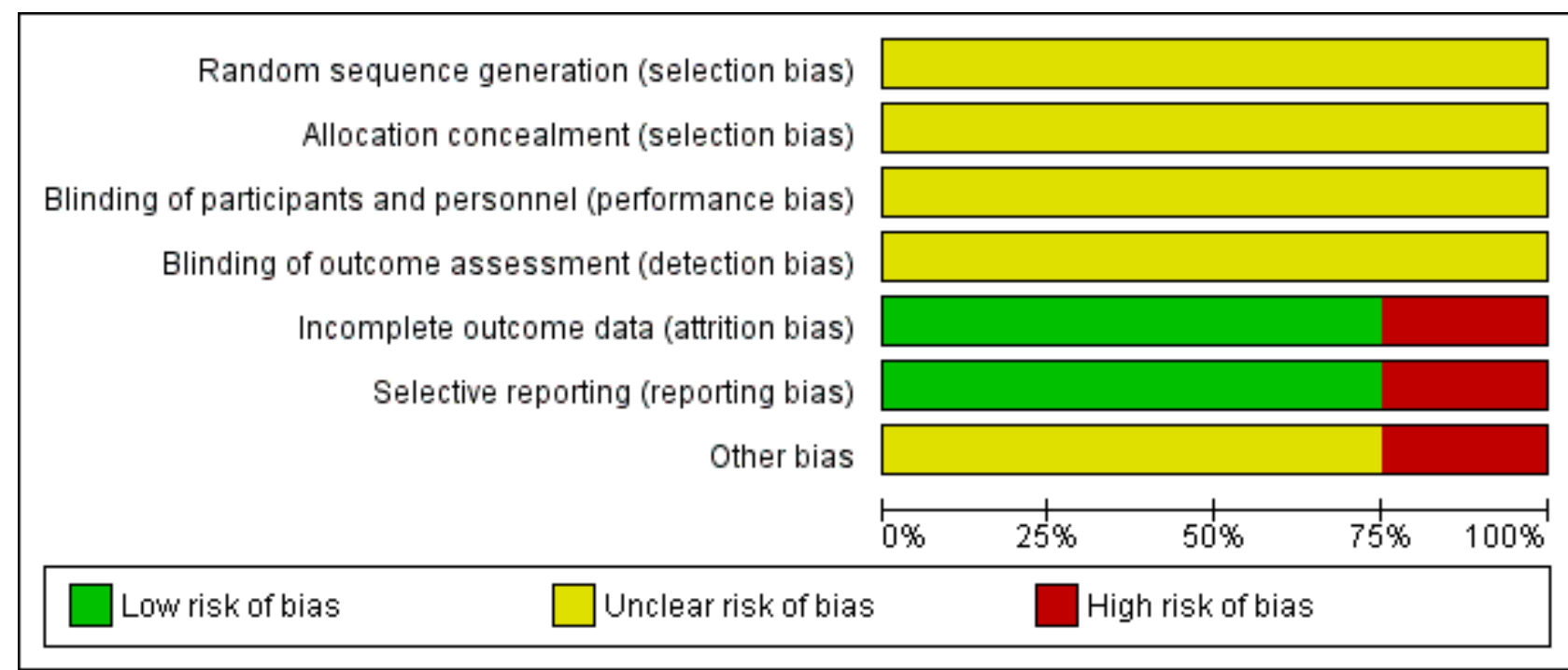


Figure 3. 'Risk of bias' summary: review authors' judgements about each risk of bias item for each included study.

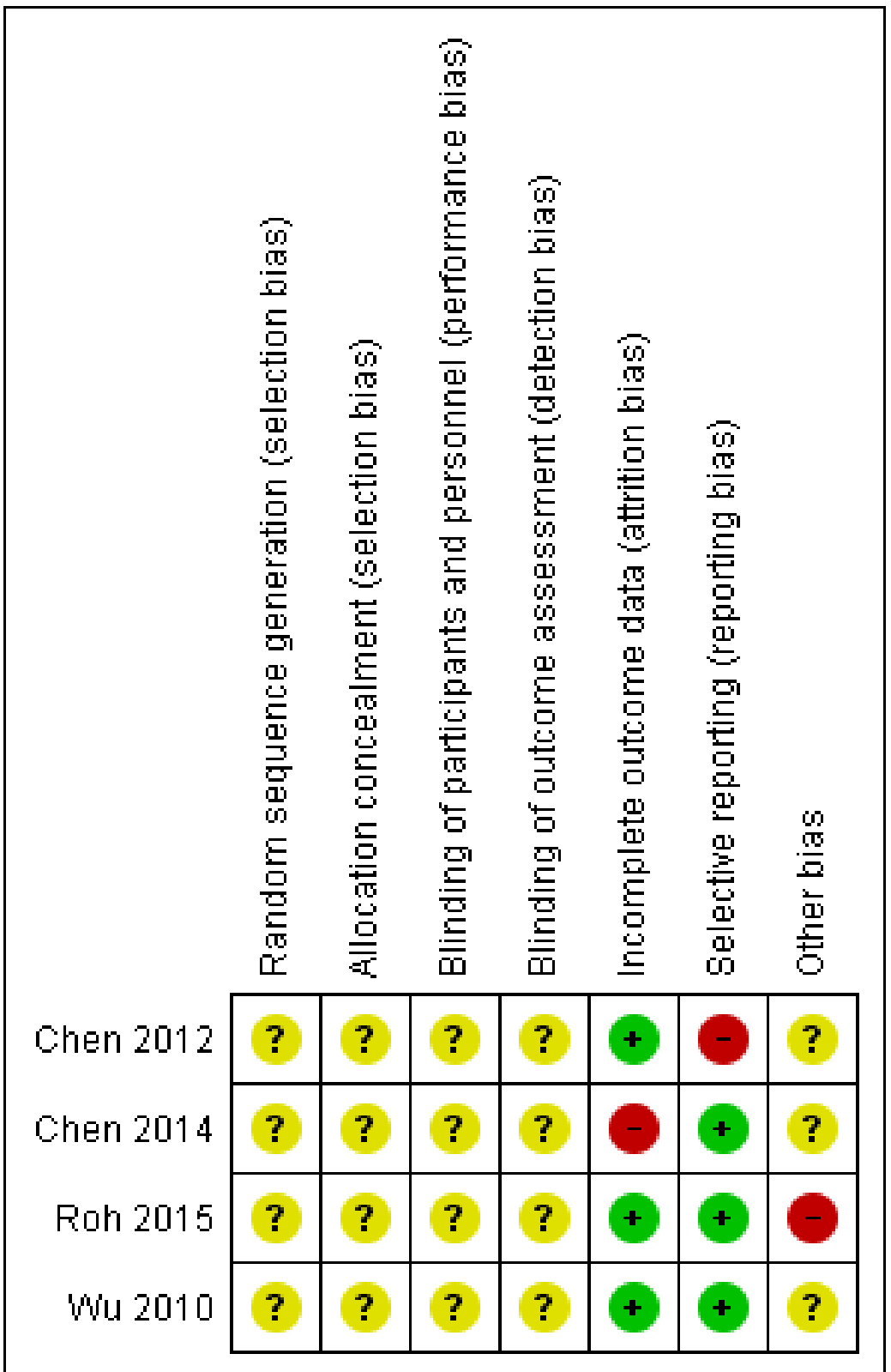

\section{Allocation}

There was no statement regarding the method used to generate and conceal the allocation sequence in any of the included studies. We determined this to indicate unclear risk of selection bias (Figure 2; Figure 3).

\section{Blinding}

There was no detailed description regarding the blinding of participants and personnel in any of the included studies. Some outcomes, such as subjective bladder dysfunction, quality of sexual life, and quality of life, are likely to be influenced by lack of blinding. We, therefore, determined this domain to be at unclear risks of performance bias and detection bias (Figure 2; Figure 3).

\section{Incomplete outcome data}

Rates of incomplete outcome data in Chen 2012 and Roh 2015 were approximately $8 \%$ and $4 \%$, respectively. In Wu 2010, all participants were analysed for all outcomes and there was no missing data. We, therefore, judged Chen 2012; Roh 2015; and Wu 2010 as having low risk of attrition bias. In Chen 2014, only 16 women (24.6\%) in both groups had undergone the urodynamic study to evaluate postoperative bladder functions ( 7 or $23.3 \%$ in the nerve-sparing group and 9 or $25.7 \%$ in the standard surgery group) which was one of the primary outcomes of interest in this study. We, therefore, judged Chen 2014 as having high risk of attrition bias (Figure 2; Figure 3). 


\section{Selective reporting}

All potential relevant outcomes were reported in Chen 2014; Roh 2015; and Wu 2010, so we judged these studies as having low risk of reporting bias. The two-year DFS reported in Chen 2012 was considered to be too short for determining survival outcome of women with early stage cervical cancer, indicating high risk of bias secondary to selective reporting (Figure 2; Figure 3).

\section{Other potential sources of bias}

In Roh 2015, the analyses were not based on an intention-to-treat basis, as they randomised 92 women, but included only women with an adequate follow-up duration of more than one year after the surgery in the analyses ( 86 women; 40 in standard surgery and 46 in nerve-sparing surgery). We therefore determined Roh 2015 as having high risk for this domain. Information in Chen 2012; Chen 2014; and Wu 2010 were insufficient for assessment of whether an important risk of bias existed (Figure 2; Figure 3).

\section{Effects of interventions}

See: Summary of findings for the main comparison

\section{Primary outcomes}

\section{Overall survival}

Chen 2012, evaluated 25 women with median follow-up of 34 months and found one patient, who underwent nerve-sparing radical hysterectomy, developed distant metastasis and died 11 months after operation. Roh 2015, assessing 86 women with a median follow-up of 111 months in the nerve-sparing group and 101 months in the standard surgery group, observed that one patient, who underwent nerve-sparing radical hysterectomy, died after developing liver and lung metastases. No women assigned to standard radical hysterectomy in either of the included studies died from any cause (Table 1). Thus, we could not calculate the hazard ratio of death from these two included studies. The remaining two included studies did not report data on overall survival (Chen 2014; Wu 2010).

\section{Intermittent self-catheterisation (ISC) at one month after the operation}

No information on ISC at one month after the operation was reported in any of the included studies. In Roh 2015, ISC had to be performed in three of the 40 women who were allocated to the standard radical hysterectomy group, but in none who allocated to the nerve-sparing group $(7.5 \%$ versus $0 \%, \mathrm{P}<0.001)$. However, there was no detailed description regarding the criteria for ISC in this study.

\section{Quality of life}

Wu 2010 reported health-related quality of life evaluated one year after operation using the Functional Assessment of Cancer Therapy- cervical cancer (FACT-CX). Higher values in this assessment represent better quality of life (Webster 2003). The authors of this study stated in the discussion section of their published article that the quality of life among women in the nerve-sparing group was better than reported among women in the standard operation group. This statement, however, contradicts results reported, which noted that women assigned to nerve-sparing surgery had lower scores than those reported in the standard surgery group $(5.36 \pm 2.47$ versus $22.33 \pm 8.38$, respectively; Wu 2010). We contacted the author to ask about this inconsistency, but we have received no response. Thus, any analysis for this outcome was not performed.

\section{Secondary outcomes}

Time to postvoid residual volume of urine (PVR) $\leq 50 \mathrm{~mL}$ after operation

Meta-analysis assessing 111 women (Chen 2012; Roh 2015) showed that women who had nerve-sparing surgery had shorter time to $\mathrm{PVR} \leq 50 \mathrm{~mL}$ than those given standard radical hysterectomy (mean difference (MD) -13.21 days; 95\% confidence interval (CI) -24.02 to -2.41 ; Analysis 1.1). The percentage of variability in effect estimates due to heterogeneity rather than to chance may represent considerable heterogeneity $(12=92 \%)$.

\section{Time to postvoid residual volume of urine $(P V R) \leq 100 \mathrm{~mL}$ after operation}

Meta-analysis assessing 58 women (Chen 2014; Wu 2010) observed a shorter time to PVR $\leq 100 \mathrm{~mL}$ among women undergoing nervesparing surgery compared to those who underwent standard radical hysterectomy (MD -9.59 days; $95 \% \mathrm{Cl}-16.28$ to -2.90 ; Analysis 1.2) see Differences between protocol and review). The percentage of variability in effect estimates due to heterogeneity rather than to chance may represent moderate heterogeneity $(12=57 \%)$.

\section{Postvoid residual volume of urine (PVR) one month, three months, six months, and 12 months after operation}

Roh 2015 reported PVR at one month, three months, and 12 months in 86 women following radical hysterectomy. Women undergoing nerve-sparing surgery had lower PVR as evaluated over these three time points than those who underwent standard radical hysterectomy (at one month; MD $-45.25 ; 95 \% \mathrm{Cl}-59.81$ to -30.69 ; at three months; MD $-41.75 ; 95 \% \mathrm{Cl}-59.40$ to -24.10 ; and at 12 months; MD -26.75; $95 \% \mathrm{Cl}-36.67$ to -16.83 ; Analysis 1.3; Analysis 1.4: Analysis 1.5). No information on PVR at six months after operation was reported in any of the included studies.

\section{Adverse events (excluding bladder dysfunction)}

Meta-analysis assessing 180 women (Chen 2014; Roh 2015; Wu 2010) showed no differences in risk of perioperative complications between women who underwent nerve-sparing radical hysterectomy and those who underwent standard radical hysterectomy (risk ratio (RR) $0.55 ; 95 \% \mathrm{Cl} 0.24$ to 1.26 ; Analysis 2.1). However, these studies did not report the severity of adverse event in details (see Differences between protocol and review). The percentage of variability in effect estimates due to heterogeneity rather than to chance was not important $(12=0 \%)$. Table 2 displays the types of perioperative complications reported in Chen 2014; Roh 2015; and Wu 2010. No information on perioperative complication was reported in Chen 2012.

\section{Subjective urinary symptoms}

Roh 2015 reported subjective urinary symptoms among the two comparison groups using a standard self-administered questionnaire of International Prostate Symptom Score (IPPS). Lower IPPS values represent better urinary function (Barry 1992). Women undergoing nerve-sparing surgery had lower score evaluated at one months (MD $-3.25 ; 95 \% \mathrm{Cl}-5.91$ to -0.59 ), three months (MD -7.00; $95 \% \mathrm{Cl}-8.92$ to -5.08 ), and 12 months (MD -7.00; 
$95 \% \mathrm{Cl}-9.67$ to -4.33$)$ than those who underwent standard radical hysterectomy (Analysis 3.1; Analysis 3.2 and Analysis 3.3).

\section{Disease-free survival (DFS)}

Roh 2015 assessed 86 women and found no difference in the risk of cancer recurrence between women undergoing nerve-sparing surgery and those who underwent standard radical hysterectomy (hazard ratio (HR) $0.63 ; 95 \% \mathrm{Cl} 0.00$ to 106.95); Analysis 4.1). We estimated HRs indirectly from the published data. However, $\mathrm{HR}$ in this study was not adjusted for important prognostic factors. In addition, a remarkably wide range of associated $95 \%$ $\mathrm{Cls}$, which included the value of no difference, might preclude drawing a meaningful conclusion regarding this outcome. In Chen 2012 , one patient in the nerve-sparing group experienced disease recurrence nine months after operation, while none who were assigned to standard radical hysterectomy developed recurrence of disease. Thus, we cannot calculate the HR of freedom from cancer recurrence in this study. Wu 2010 and Chen 2014 did not report data on DFS.

\section{Cancer recurrence}

The rate of cancer recurrence was reported in two of the four included studies (Chen 2012; Roh 2015). In Chen 2012, one patient in the nerve-sparing group (one of 12 women) developed recurrence in the sigmoid colon, while none of the 13 women allocated to the standard surgery group had cancer recurrence (Table 1). In Roh 2015, approximately 6.5\% of women assigned to the nerve-sparing group experienced recurrent cervical cancer, which was comparable to the $5.0 \%$ reported for women undergoing standard radical hysterectomy (Table 1 ). When we pooled the data from these two included studies (Chen 2012; Roh 2015), no difference was demonstrated ( 111 women; RR $1.62 ; 95 \% \mathrm{Cl} 0.35$ to 7.38; Analysis 5.1). The percentage of variability in effect estimates due to heterogeneity rather than to sampling error (chance) was not important $(12=0 \%)$.

\section{Urinary tract infection during the month after operation}

No information on urinary tract infection over the month following surgery was reported in any of the included studies.

\section{Maximal urethral closure pressure (MUCP)}

High MUCP indicates good urinary bladder function (Laterza 2015). Roh 2015 reported that women undergoing nerve-sparing radical hysterectomy had higher MUCP assessed at one month after operation than women assigned to the standard surgery group (MD $14.20 \mathrm{cmH}_{2} \mathrm{O}$; $95 \mathrm{Cl} 4.87$ to 23.53; Analysis 6.1). Meta-analysis of 115 women obtained from Roh 2015 and Wu 2010 assessing MUCP six to 12 months after operation showed that the higher MUCP among women undergoing nerve-sparing surgery persisted (MD $14.26 \mathrm{cmH}_{2} \mathrm{O}$; $95 \% \mathrm{Cl} 5.57$ to 22.94; Analysis 6.2).

\section{Maximum flow rate (MFR) and number of women with low MFR}

High MFR represents good detrusor contractility (Laterza 2015). In Roh 2015, women undergoing nerve-spring radical hysterectomy had higher MFR assessed at one month following operation than women allocated in the standard surgery group (MD $9.25 \mathrm{~mL} / \mathrm{sec}$; $95 \% \mathrm{Cl} 6.11$ to 12.39 ; Analysis 7.1). Meta-analysis of 131 women (Chen 2014; Roh 2015; Wu 2010) showed a persistent higher MFR assessed at six to 12 months after operation among women in the nerve-sparing group than those who underwent standard operation (MD $6.39 \mathrm{~mL} / \mathrm{sec} ; 95 \% \mathrm{Cl} 4.68$ to 8.11 ; Analysis 7.2). The percentage of variability in effect estimates due to heterogeneity rather than to chance was not important $(12=0 \%)$. No information on the number of women with low MFR was reported in any of the included studies.

\section{Detrusor pressure at maximum flow and number of women with low detrusor pressure}

Roh 2015 noted lower detrusor pressure at one month after operation among women undergoing nerve-sparing radical hysterectomy than those in standard surgery group (MD-24.00 $\mathrm{cmH}_{2} \mathrm{O} ; 95 \mathrm{Cl}-39.46$ to -8.54; Analysis 8.1). However, meta-analysis assessing 102 women six to 12 months after operation showed a higher detrusor pressure among women undergoing nerve-sparing surgery (MD $9.49 \mathrm{cmH}_{2} \mathrm{O} ; 95 \% \mathrm{Cl} 0.83$ to 18.16; Analysis 8.2). The percentage of variability in effect estimates due to heterogeneity rather than to chance may represent moderate heterogeneity $\left(1^{2}=\right.$ $46 \%)$. No information on the number of women with low detrusor pressure at maximum flow was reported in any of the included studies.

\section{Sexual dysfunction}

Only Chen 2014 reported the impact of nerve-sparing radical hysterectomy on sexual function using Female Sexual Function Index (FSFI) at one year following surgery. Higher FSFI scores represent better quality of sexual life. Chen 2014 observed that women undergoing laparoscopic nerve-sparing radical hysterectomy had higher FSFI scores than women in the standard surgery group (23.34 \pm 3.69 versus $17.57 \pm 2.28$; Chen 2014). However, the authors did not report the number of participants assessed in each comparison group. We, therefore, could not analyse the relative effect of different surgical techniques on the sexual functions among the comparison groups.

\section{Cost-effectiveness}

The included studies did not report on cost-effectiveness.

\section{Operative time}

Meta-analysis of three included studies, which assessed a total of 140 women, showed that there was no difference in terms of operative time between the groups (MD 11.57 minutes; $95 \% \mathrm{Cl}$ -10.13 to 33.27 ; Analysis 9.1). The percentage of the variability in effect estimates due to heterogeneity rather than chance may represent moderate heterogeneity $\left(1^{2}=60 \%\right)$. We did not include Chen 2014 in the meta-analysis for this outcome due to insufficient data.

\section{Estimated blood loss}

Meta-analysis of three included studies, which evaluated a total of 140 women, showed no difference in the amount of estimated blood loss between women who underwent nervesparing operation and those who underwent standard operation (MD -36.89 mL; $95 \mathrm{Cl}-200.12$ to 126.35; Analysis 10.1). The percentage of variability in effect estimates due to heterogeneity rather than chance was not important $(12=38 \%)$. We did not include Chen 2014 in the meta-analysis for this outcome due to insufficient data. 


\section{DISCUSSION}

This review compared nerve-sparing radical hysterectomy to standard radical hysterectomy in individuals with early stage cervical cancer. Four small randomised controlled trials (RCTs) met the review inclusion criteria.

\section{Summary of main results}

We identified four small RCTs assessing a total of 205 women, but most of our analyses are based on fewer numbers of studies/ women. The effectiveness and safety of nerve-sparing radical hysterectomy were incompletely assessed. All included studies had small sample sizes with an unclear risk of bias in most of the domains assessed, due to insufficient information provided. In addition, the results of the main comparisons were based on low- to very low-certainty evidence. The very low-certainty evidence for disease-free survival (DFS) and lack of information for overall survival indicate that the oncological safety of nervesparing radical hysterectomy for women with early stage cervical cancer remains unknown. However, two women assigned to nervesparing surgery died (one from Chen 2012 and one from Roh 2015), whereas no deaths occurred among women assigned to standard radical hysterectomy (Table 1 ). This finding may raise a concern about the safety of nerve-sparing radical hysterectomy for early stage cervical cancer, but the numbers are too small to draw meaningful conclusions and we are unable to tell whether this is due to chance or represents a true difference.

Nerve-sparing radical hysterectomy minimised the risk of postoperative bladder dysfunction. When compared to women who underwent standard radical hysterectomy, those who underwent nerve-sparing radical hysterectomy exhibited shorter times to small volume of postvoid residual urine (PVR), lower volume of PVR, and higher urethral closure pressure and flow rate as assessed by urodynamic study, indicating better urinary bladder function. In addition, women in the nerve-sparing group were less likely to complain about urinary tract symptoms. There was no difference between the comparison groups with regard to measures of perioperative complications, estimated blood loss, and operative time.

\section{Overall completeness and applicability of evidence}

Primary outcomes of this review were overall survival, rate of intermittent self-catheterisation at one month following surgery, and quality of life. Only two of the included studies, including 111 women, reported survival data. As there had been two deaths among women in the nerve-sparing group, but none in women assigned to standard surgery group, the relative effect measures on the risk of death could not be estimated (Table 1). None of the four included studies reported rate of intermittent selfcatheterisation at one month following surgery. One included study reported health-related quality of life, but the reported data were inconsistent throughout the published article, precluding analysis of this outcome. Therefore, there were no available data for the analysis of primary outcomes of interest in this review.

Secondary outcomes of this review included postoperative bladder function, DFS, cancer recurrence, cost-effectiveness, sexual functions, and perioperative outcomes. Although there were no differences between women undergoing nerve-sparing radical hysterectomy and those undergoing standard radical hysterectomy in terms of progression-free survival or rate of cancer recurrence. However, these findings should be interpreted with caution as there were only five women who experienced recurrent disease, which is likely to be too infrequent to draw a meaningful conclusion. One included study reported postoperative sexual functions. However, the data were insufficient for analysis.

None of the four included studies reported data on urinary tract infection or cost-effectiveness. We could not analyse the relative effect of the two surgical techniques on quality of life and sexual functions due to insufficient or inconsistent reported data.

Similar to all systematic reviews, applicability of evidence is limited by the quantity and quality of the review results. The lack of data regarding all primary outcomes of interest in this review and the low to very low certainty of available evidences regarding these outcomes (see Quality of the evidence) may make it difficult to generalise the findings of this review. Another potential limitation to the applicability of this review is that the operations in three of the four included studies were performed via laparotomy. Only one small study, assessing 65 women, used laparoscopy as the surgical approach, but analyses of some important outcomes (i.e. time to PVR $<100 \mathrm{~mL}$ and results of the postoperative urodynamic evaluation) were based on fewer (29 women and 16 women for each outcome, respectively). In addition, this study did not report survival rate and rate of cancer recurrence. As such, the applicability of the existing evidence to a group of women undergoing laparoscopic radical hysterectomy may be questionable.

Some outcome measures (i.e. quality of life, lower urinary tract symptoms and sexuality) may be affected by culture and ethnicity (Gotay 2002; Heinemann 2016; Maserejian 2014). As all four included studies were undertaken in Asian countries, findings of this review may not be fully applicable to populations in different settings.

\section{Quality of the evidence}

The lack of large, high-quality RCT data is the fundamental limitation of this review. We identified four small RCTs with unclear risk of bias in most of the domains assessed. In addition, there was insufficient information available to assess the risks of selection and detection biases, which might preclude drawing a meaningful conclusion from the review. Another limitation of this review is the small number of included studies, which is reflected by the very large and non-informative $95 \%$ confidence intervals in some comparisons. The relative small sample size also has the potential to affect its accuracy with regard to statistical heterogeneity (IntHout 2015; von Hippel 2015). Thus, we applied the randomeffects model for all meta-analyses.

We assessed the certainty of evidence using the GRADE approach for the main outcomes (see Summary of findings for the main comparison). Based on the concerns regarding the unclear risk of the selection, performance, and detection biases with the small sample size, we downgraded the evidence to low certainty for time to postvoid residual volume of urine $\leq 50 \mathrm{~mL}$, PVR volume of urine one month following operation, and rate of perioperative complications (Figure 2; Figure 3).

We downgraded the evidence to very low certainty for the estimation of DFS among the two comparison groups based on 
the unclear risk of bias for most of the domains assessed, the small sample size and small number of reported events, and application of unadjusted hazard ratios in the analyses (Figure 2; Figure 3). None of the included studies reported rate of intermittent self-catheterisation following operation. In addition, we could not determine the relative effect of the two different surgeries on the overall survival and quality of life as there had been insufficient or inconsistent data reported.

The very low-certainty evidence for DFS and lack of information for estimating the difference in overall survival noted in this review indicate that the oncological safety of nerve-sparing radical hysterectomy remains an issue of debate.

\section{Potential biases in the review process}

With assistance from the Information Specialist, Cochrane Gynaecological, Neuro-oncology \& Orphan Cancer Group, we conducted a comprehensive search, including a thorough search of the grey literature, conference proceedings, key textbooks, citation lists of included studies, and registered databases of ongoing trials. Two review authors independently sifted through all studies and extracted data. We restricted included studies to RCTs in order to obtain the best evidence. Thus, we have attempted to lessen bias in the review process. However, as there were few studies that were included in the review, there remains the possibility that there may be other unpublished studies that we did not discover. We were unable to assess this possibility as the analyses were limited to meta-analyses that examined either a single or just small number of studies.

Another source of potential biases is the incomplete or inconsistent data reported in some included studies. Despite our best efforts, we were not able to get detailed data from the authors of the included studies. There were no issues associated with conflicts of interests of the authors of this review.

\section{Agreements and disagreements with other studies or reviews}

Several systematic reviews comparing nerve-sparing radical hysterectomy versus standard radical hysterectomy for early stage cervical cancer have been published in recent years (Aoun 2015; Basaran 2015; Kim 2015b; Long 2014; van Gent 2016; Xue 2016). Overall, the conclusions drawn from these reviews are consistent in that nerve-sparing radical hysterectomy resulted in less bladder dysfunction than standard radical hysterectomy without compromising the survival. However, this evidence should be interpreted with caution, as all of these systematic reviews included a body of non-randomised evidence obtained from various forms of non-randomised studies (NRSs). Despite lacking randomisation, high-quality NRSs can sometimes complement the evidence from randomised controlled trials (RCTs) (Schünemann 2013). However, it has been acknowledged that there is no standard surgical techniques for nerve-sparing radical hysterectomy. Therefore, there is likely a wide variation in surgical techniques used for this procedure across various settings (Sakuragi 2015). In addition, NRSs undertaken to evaluate nervesparing radical hysterectomy usually involved small sample sizes. These may be key limitations of NRSs, leading to a substantial heterogeneity when attempting to perform meta-analyses, as has been noted in previous reviews (Kim 2015b; Long 2014; van Gent
2016; Xue 2016). As such, we did not include NRSs, as they were unlikely to contribute to the certainty of evidence.

In this review, all included studies were RCTs comparing two techniques for performing Piver class III radical hysterectomy in order to diminish the amount of variation in the procedure. Similar to previous reviews, we found that nerve-sparing radical hysterectomy may lessen bladder dysfunction following operation compared to standard radical hysterectomy. However, there is insufficient evidence from RCTs to ascertain the oncological safety of nerve-sparing radical hysterectomy for women with early stage cervical cancer.

\section{AUTHORS' CONCLUSIONS}

\section{Implications for practice}

Low- to very low-certainty evidence obtained from the four small randomised controlled trials (RCTs) indicated that women undergoing nerve-sparing radical hysterectomy are at decreased risk of postoperative bladder dysfunction when compared to those who underwent standard radical hysterectomy. However, these trials had insufficient numbers of women and there was a lack of data regarding clinically important outcomes.

In addition, there is insufficient evidence to indicate whether nerve-sparing radical hysterectomy offers an oncological efficacy equivalent to standard radical hysterectomy for women with early stage cervical cancer.

\section{Implications for research}

We were not able to estimate the relative effect of nerve-sparing surgery compared to standard surgery on overall survival, quality of life, and sexual dysfunction, due to lack of long-term outcome data. As recurrence rates are low in this group of patients, an adequately powered, international, high-quality, randomised controlled trial is necessary to re-assess whether nerve-sparing radical hysterectomy is an oncological equivalent to, and results in less morbidity than, standard radical hysterectomy for women with early stage cervical cancer.

Over the past 10 to 20 years, a minimally invasive radical hysterectomy has been widely introduced (Park 2017; Spirtos 2002). Several studies have reported high feasibility and safety of nerve-sparing radical hysterectomy performing via laparoscopic or robotic-assisted techniques (Chong 2013; Kim 2015a; Kyo 2016). As stated earlier, the surgical approach in one included study of this review was laparoscopic radical hysterectomy (Chen 2014; see Characteristics of included studies). There is one ongoing study comparing conventional versus nerve-sparing hysterectomy using laparoscopic approach (Gaballa 2015; see Characteristics of ongoing studies). However, early findings from the multicentre, international Phase III randomised study suggested that women with early stage cervical cancer who underwent laparoscopic or robotic-assisted radical hysterectomy carried higher rates of disease recurrence and worse survival than women who underwent surgery via an open approach (Ramirez 2018). These unexpected findings may raise further questions of whether minimally invasive radical hysterectomy continues to be a viable option for future research in surgical treatment for early stage cervical cancer. 


\section{ACKN OWLEDGEMENTS}

We would like to thank Jo Morrison for clinical and editorial advice; Jo Platt for designing the search strategy; Gail Quinn, Clare Jess and Tracey Harrison for their contributions to the editorial process; and Dylan Southard for assisting with English language presentation.

This project was supported by the National Institute for Health Research, via Cochrane infrastructure funding to the Cochrane
Gynaecological, Neuro-oncology and Orphan Cancers Group. The views and opinions expressed therein are those of the review authors and do not necessarily reflect those of the Systematic Reviews Programme, NIHR, NHS, or the Department of Health.

We would like to thank the referees for many helpful suggestions and comments, some of these referees include Janos Balega, Elly Brockbank, Andy Bryant, Fani Kokka and John Tidy. 


\section{R E F E R E N C E S}

\section{References to studies included in this review}

\section{Chen 2012 \{published data only\}}

Chen C, Li W, Li F, Liu P, Zhou J, Lu L, et al. Classical and nervesparing radical hysterectomy: an evaluation of the nerve trauma in cardinal ligament. Gynecologic Oncology 2012;125(1):245-51.

\section{Chen 2014 \{published data only\}}

Chen L, Zhang WN, Zhang SM, Yang ZH, Zhang P. Effect of laparoscopic nerve-sparing radical hysterectomy on bladder function, intestinal function recovery and quality of sexual life in patients with cervical carcinoma. Asian Pacific Journal of Cancer Prevention 2014;15(24):10971-5.

\section{Roh 2015 \{published data only\}}

Roh JW, Lee DO, Suh DH, Lim MC, Seo SS, Chung J, et al. Efficacy and oncologic safety of nerve-sparing radical hysterectomy for cervical cancer: a randomized controlled trial. Journal of Gynecologic Oncology 2015;26(2):90-9.

\section{Wu 2010 \{published data only\}}

Wu J, Liu X, Hua K, Hu C, Chen X, Lu X. Effect of nerve-sparing radical hysterectomy on bladder function recovery and quality of life in patients with cervical carcinoma. International Journal of Gynecological Cancer 2010;20(5):905-9.

\section{References to studies excluded from this review}

\section{Barbic 2012 \{published data only\}}

Barbic M, Rakar S, Levicnik A, Di Stefano AB. Comparison of nerve content in removed parametrial tissue after classic radical hysterectomy and nerve-sparing radical hysterectomyhistologic evaluation. European Journal of Gynaecological Oncology 2012;33(1):21-4

\section{Bogani 2014 \{published data only\}}

Bogani G, Cromi A, Uccella S, Serati M, Casarin J, Pinelli C, et al. Nerve-sparing versus conventional laparoscopic radical hysterectomy: a minimum 12 months' follow-up study. International Journal of Gynecological Cancer 2014;24(4):787-93.

\section{Ceccaroni 2010 \{published data only\}}

Ceccaroni M, Pontrelli G, Spagnolo E, Scioscia M, Bruni F, Paglia A, et al. Parametrial dissection during laparoscopic nerve-sparing radical hysterectomy: a new approach aims to improve patients' postoperative quality of life. American Journal of Obstetrics and Gynecology 2010;202(3):320.e1-2.

\section{Ceccaroni 2012 \{published data only\}}

Ceccaroni M, Roviglione G, Spagnolo E, Casadio P, Clarizia R, Peiretti $M$, et al. Pelvic dysfunctions and quality of life after nerve-sparing radical hysterectomy: a multicenter comparative study. Anticancer Research 2012;32(2):581-8.

\section{Charoenkwan 2010 \{published data only}

Charoenkwan K. A simplified technique for nerve-sparing type III radical hysterectomy: by reorganizing their surgical sequence, surgeons could more easily identify key nerves. American Journal of Obstetrics and Gynecology 2010;203(6):600.e1-6.

\section{Cibula 2010 \{published data only\}}

Cibula D, Velechovska P, Slama J, Fischerova D, Pinkavova I, Pavlista $\mathrm{D}$, et al. Late morbidity following nerve-sparing radical hysterectomy. Gynecologic Oncology 2010;116(3):506-11.

\section{Ditto 2009 \{published data only\}}

Ditto A, Martinelli F, Borreani C, Kusamura S, Hanozet F, Brunelli $C$, et al. Quality of life and sexual, bladder, and intestinal dysfunctions after class III nerve-sparing and class II radical hysterectomies: a questionnaire-based study. International Journal of Gynecological Cancer 2009;19(5):953-7.

\section{Hockel 2000 \{published data only\}}

Hockel M, Naumann G, Alexander H, Horn LC, Fischer U, Schmidt F, et al. Nerve-sparing radical hysterectomy: il. Results after three years. Geburtshilfe und Frauenheilkunde 2000;60(6):320-5

\section{Kanao 2014 \{published data only\}}

Kanao H, Fujiwara K, Ebisawa K, Hada T, Ota Y, Andou M. Various types of total laparoscopic nerve-sparing radical hysterectomies and their effects on bladder function. Journal of Gynecologic Oncology 2014;25(3):198-205.

Kim 2017 \{published data only\}

Kim HS, Kim M, Luo Y, Lee M, Song YS. Favorable factors for preserving bladder function after nerve-sparing radical hysterectomy: a protocol-based validation study. Journal of Surgical Oncology 2017;116(4):492-9.

\section{Milani 1991 \{published data only\}}

Milani R, Maggioni A, Scalambrino S, Landoni F, Caruso O, Mangioni $\mathrm{C}$. Bladder function following randomization to two different radical hysterectomy procedures: A prospective study. International Urogynecology Journal 1991;2(2):77-8.

Querleu 2002 \{published data only\}

Querleu D, Narducci F, Poulard V, Lacaze S, Occelli B, Leblanc E, et al. Modified radical vaginal hysterectomy with or without laparoscopic nerve-sparing dissection: a comparative study. Gynecologic Oncology 2002;85(1):154-8.

\section{Raspagliesi 2006 \{published data only\}}

Raspagliesi F, Ditto A, Fontanelli R, Zanaboni F, Solima E, Spatti G, et al. Type II versus Type III nerve-sparing radical hysterectomy: comparison of lower urinary tract dysfunctions. Gynecologic Oncology 2006;102(2):256-62.

\section{Raspagliesi 2017 \{published data only\}}

Raspagliesi F, Bogani G, Spinillo A, Ditto A, Bogliolo S, Casarin J, et al. Introducing nerve-sparing approach during minimally invasive radical hysterectomy for locally-advanced cervical cancer: a multi-institutional experience. European Journal of Surgical Oncology 2017;43(11):2150-6. 
Sakuragi 2015 \{published data only\}

Sakuragi N. Nerve-sparing radical hysterectomy: time for a new standard of care for cervical cancer?. Journal of Gynecologic Oncology 2015;26(2):81-1.

\section{Shi 2016 \{published data only\}}

Shi R, Wei W, Jiang P. Laparoscopic nerve-sparing radical hysterectomy for cervical carcinoma: emphasis on nerve content in removed cardinal ligaments. International Journal of Gynecological Cancer 2016;26(1):192-8.

\section{Skret-Magierlo 2010 \{published data only\}}

Skret-Magierlo J, Narog M, Kruczek A, Kluza R, Kluz T, Magon T, et al. Radical hysterectomy during the transition period from traditional to nerve-sparing technique. Gynecologic Oncology 2010;116(3):502-5.

\section{Su 2017 \{published data only\}}

Su Y, Zhang M, Zhang W, Shi H. Application research on nerve sparing radical hysterectomy for rectal function. Pakistan Journal of Pharmaceutical Sciences 2017;30(1 Suppl):329-34.

\section{Todo 2006 \{published data only\}}

Todo Y, Kuwabara M, Watari H, Ebina Y, Takeda M, Kudo M, et al. Urodynamic study on postsurgical bladder function in cervical cancer treated with systematic nerve-sparing radical hysterectomy. International Journal of Gynecological Cancer 2006;16(1):369-75.

\section{Tseng 2012 \{published data only\}}

Tseng CJ, Shen HP, Lin YH, Lee CY, Wei-Cheng Chiu W. A prospective study of nerve-sparing radical hysterectomy for uterine cervical carcinoma in Taiwan. Taiwanese Journal of Obstetrics and Gynecology 2012;51(1):55-9.

\section{Yang 2016 \{published data only\}}

Yang Y, Qin T, Zhang W, Wu Q, Yang A, Xu F. Laparoscopic nervesparing radical hysterectomy for bulky cervical cancer $(>6 \mathrm{~cm})$ after neoadjuvant chemotherapy: a multicenter prospective cohort study. International Journal of Surgery 2016;34:35-40.

\section{References to ongoing studies}

\section{Gaballa 2015 \{unpublished data only\}}

Feasibility and functional outcome of laparoscopic nerve sparing radical hysterectomy (NCT02524756). Ongoing study November 2014.

\section{Additional references}

\section{Aoun 2015}

Aoun F, Albisinni S, Peltier A, Maoula A, van Velthoven R, Roumeguère $T$. Lower urinary tract dysfunction following nerve sparing radical hysterectomy: A systematic review. Progress in Urology 2015;:S1166-7087(15):690-9.

\section{Barry 1992}

Barry MJ, Fowler FJ Jr, O'Leary MP, Bruskewitz RC, Holtgrewe HL, Mebust WK, et al. The American Urological Association symptom index for benign prostatic hyperplasia.
The measurement committee of the American Urological Association. Journal of Urology 1992;148(5):1549-57.

\section{Basaran 2015}

Basaran D, Dusek L, Majek O, Cibula D. Oncological outcomes of nerve-sparing radical hysterectomy for cervical cancer: a systematic review. Annals of Surgical Oncology 2015;22(9):3033-40.

\section{Butler-Manuel 2000}

Butler-Manuel SA, Buttery LD, A'Hern RP, Polak JM, Barton DP. Pelvic nerve plexus trauma at radical hysterectomy and simple hysterectomy: the nerve content of the uterine supporting ligaments. Cancer 2000;89(4):834-41.

\section{Charoenkwan 2006}

Charoenkwan K, Srisomboon J, Suprasert P, Tantipalakorn C, Kietpeerakool C. Nerve-sparing class III radical hysterectomy: a modified technique to spare the pelvic autonomic nerves without compromising radicality. International Journal of Gynecological Cancer 2006;16(4):1705-12.

\section{Cherny 2015}

Cherny NI, Sullivan R, Dafni U, Kerst JM, Sobrero A, Zielinski C, et al. A standardised, generic, validated approach to stratify the magnitude of clinical benefit that can be anticipated from anticancer therapies: the European Society for Medical Oncology Magnitude of Clinical Benefit Scale (ESMO-MCBS). Annals of Oncology 2015;26(8):1547-73.

\section{Chong 2013}

Chong GO, Lee YH, Hong DG, Cho YL, Park IS, Lee YS. Robot versus laparoscopic nerve-sparing radical hysterectomy for cervical cancer: a comparison of the intraoperative and perioperative results of a single surgeon's initial experience. International Journal of Gynecological Cancer 2013;23(6):1145-9.

\section{Cibula 2011}

Cibula D, Abu-Rustum NR, Benedetti-Panici P, Köhler C, Raspagliesi F, Querleu D, et al. New classification system of radical hysterectomy: emphasis on a three-dimensional anatomic template for parametrial resection. Gynecologic Oncology 2011;122(2):264-8.

\section{Covidence [Computer program]}

Veritas Health Innovation. Covidence. Version accessed 27 September 2017. Melbourne, Australia: Veritas Health Innovation, 2017.

\section{CTCAE 2010}

$\mathrm{NCl}$. Common Terminology Criteria for Adverse Events v4.03. National Institutes of Health, US Department of Health and Human Services (accessed 27 September 2017); Vol. publication 09-7473.

\section{Deeks 2001}

Deeks J, Altman D, Bradburn M. Statistical methods for examining heterogeneity and combining results from several studies in meta-analysis. In: Egger M, Davey Smith G, Altman DG editor(s). Systematic Reviews in Health Care: Meta-Analysis

Nerve-sparing radical hysterectomy compared to standard radical hysterectomy for women with early stage cervical cancer (stage la2 to 
in Context. 2nd Edition. London (UK): BMJ Publication Group, 2001:285-312.

\section{DeSimonian 1986}

DerSimonian R, Laird N. Meta-analysis in clinical trials. Controlled Clinical Trials 1986;7(3):177-88.

\section{EndNote [Computer program]}

Thomas Reuters. EndNote. Version x7. New York: Thomas Reuters, 2015.

\section{Ercoli 2003}

Ercoli A, Delmas V, Gadonneix P, Fanfani F, Villet R, Paparella P, et al. Classical and nerve-sparing radical hysterectomy: an evaluation of the risk of injury to the autonomous pelvic nerves. Surgical and Radiologic Anatomy 2003;25(3-4):200-6.

\section{Ferlay 2015}

Ferlay J, Soerjomataram I, Dikshit R, Eser S, Mathers C, Rebelo $\mathrm{M}$, et al. Cancer incidence and mortality worldwide: sources, methods and major patterns in GLOBOCAN 2012. International Journal of Cancer 2015;136(5):E359-86.

\section{FIGO Committee 2014}

FIGO Committee on Gynecologic Oncology. FIGO staging for carcinoma of the vulva, cervix, and corpus uteri. International Journal of Gynaecology \& Obstetrics 2014;125(2):97-8.

\section{Fujii 2007}

Fujii S, Takakura K, Matsumura N, Higuchi T, Yura S, Mandai M, et al. Anatomic identification and functional outcomes of the nerve sparing Okabayashi radical hysterectomy. Gynecologic Oncology 2007;107(1):4-13.

\section{Fujii 2008}

Fujii S. Anatomic identification of nerve-sparing radical hysterectomy: a step-by-step procedure. Gynecologic Oncology 2008;111(2 Suppl):S33-41.

\section{Gotay 2002}

Gotay CC, Holup JL, Pagano I. Ethnic differences in quality of life among early breast and prostate cancer survivors. Psychooncology 2002;11(2):103-13.

\section{GRADEpro GDT [Computer program]}

McMaster University (developed by Evidence Prime). GRADEpro GDT. Version accessed 27 September 2017. Hamilton (ON): McMaster University (developed by Evidence Prime), 2015.

\section{Greimel 2006}

Greimel ER, Kuljanic Vlasic K, Waldenstrom AC, Duric VM, Jensen PT, Singer S, et al. The European Organization for Research and Treatment of Cancer (EORTC) Quality-of-Life questionnaire cervical cancer module: EORTC QLQ-CX24. Cancer 2006;107(8):1812-22.

\section{Heinemann 2016}

Heinemann J, Atallah S, Rosenbaum T. The impact of culture and ethnicity on sexuality and sexual function. Current Sexual Health Reports 2016;8(3):144-50.

\section{Higgins 2011}

Higgins JP, Green S, editor(s). Cochrane Handbook for Systematic Reviews of Interventions Version 5.1.0 (updated March 2011). The Cochrane Collaboration, 2011. Available from handbook.cochrane.org.

\section{Hongladaromp 2014}

Hongladaromp W, Tantipalakorn C, Charoenkwan K, Srisomboon J. Locoregional spread and survival of stage IIA1 versus stage IIA2 cervical cancer. Asian Pacific Journal of Cancer Prevention 2014;15(2):887-90.

\section{Huber 2015}

Huber SA, Northington GM, Karp DR. Bowel and bladder dysfunction following surgery within the presacral space: an overview of neuroanatomy, function, and dysfunction. International Urogynecology Journal 2015;26(7):941-6.

\section{IntHout 2015}

IntHout J, loannidis JP, Borm GF, Goeman JJ. Small studies are more heterogeneous than large ones: a meta-meta-analysis. Journal of Clinical Epidemiology 2015;68(8):860-9.

\section{Jensen 2004}

Jensen PT, Klee MC, Thranov I, Groenvold M. Validation of a questionnaire for self-assessment of sexual function and vaginal changes after gynaecological cancer. Psycho-oncology 2004;13(8):577-92.

\section{Katepratoom 2014}

Katepratoom C, Manchana T, Amornwichet N. Lower urinary tract dysfunction and quality of life in cervical cancer survivors after concurrent chemoradiation versus radical hysterectomy. International Urogynecology Journal 2014;25(1):91-6.

\section{Kato 2003}

Kato T, Murakami G, Yabuki Y. A new perspective on nervesparing radical hysterectomy: nerve topography and overpreservation of the cardinal ligament. Japanese Journal of Clinical Oncology 2003;33(11):589-91.

\section{Kim 2000}

Kim SM, Choi HS, Byun JS. Overall 5-year survival rate and prognostic factors in patients with stage IB and IIA cervical cancer treated by radical hysterectomy and pelvic lymph node dissection. International Journal of Gynecologic Cancer 2000;10(4):305-12.

\section{Kim 2015a}

Kim HS, Kim TH, Suh DH, Kim SY, Kim MA, Jeong CW, et al. Success factors of laparoscopic nerve-sparing radical hysterectomy for preserving bladder function in patients with cervical cancer: a protocol-based prospective cohort study. Annals of Surgical Oncology 2015;22(6):1987-95.

\section{Kim 2015b}

Kim HS, Kim K, Ryoo SB, Seo JH, Kim SY, Park JW, et al. Conventional versus nerve-sparing radical surgery for cervical cancer: a meta-analysis. Journal of Gynecologic Oncology 2015;26(2):100-10 


\section{Kyo 2016}

Kyo S, Kato T, Nakayama K. Current concepts and practical techniques of nerve-sparing laparoscopic radical hysterectomy. European Journal of Obstetrics \& Gynecology and Reproductive Biology 2016;207:80-8.

\section{Langendam 2013}

Langendam MW, Akl EA, Dahm P, Glasziou P, Guyatt G, Schünemann HJ. Assessing and presenting summaries of evidence in Cochrane Reviews. Systematic Reviews 2013;2:81.

\section{Laterza 2015}

Laterza RM, Sievert KD, de Ridder D, Vierhout ME, Haab F, Cardozo L, et al. Bladder function after radical hysterectomy for cervical cancer. Neurourology and Urodynamics 2015;34(4):309-15.

\section{Liberati 2009}

Liberati A, Altman D, Tetzlaff J, Mulrow C, Gotzsche P, loannidis J, et al. The PRISMA statement for reporting systematic reviews and meta-analyses of studies that evaluate health care interventions: explanation and elaboration. $B M J$ 2009;339:b2700.

\section{Long 2014}

Long Y, Yao DS, Pan XW, Ou TY. Clinical efficacy and safety of nerve-sparing radical hysterectomy for cervical cancer: a systematic review and meta-analysis. PLOS One 2014;9(4):e94116.

\section{Maas 2005}

Maas CP, Kenter GG, Trimbos JB, Deruiter MC. Anatomical basis for nerve-sparing radical hysterectomy: immunohistochemical study of the pelvic autonomic nerves. Acta Obstetricia et Gynecologica Scandinavica 2005;84(9):868-74.

\section{Mahawerawat 2013}

Mahawerawat S, Charoenkwan K, Srisomboon J, Khunamornpong S, Suprasert P, Sae-Teng CT. Surgical outcomes of patients with stage IA2 cervical cancer treated with radical hysterectomy. Asian Pacific Journal of Cancer Prevention 2013;14(9):5375-8.

\section{Manchana 2009}

Manchana T, Sirisabya N, Lertkhachonsuk R, Worasethsin P, Khemapech N, Sittisomwong T, et al. Long term complications after radical hysterectomy with pelvic lymphadenectomy. Journal of the Medical Association of Thailand 2009;92(4):451-6.

\section{Mantzaris 2008}

Mantzaris G, Rodolakis A, Vlachos G, Athanasiou S, Theocharis S, Sotiripoulou ChM, et al. Magnifying lenses assisted nerve-sparing radical hysterectomy and prevention of nerve plexus trauma. International Journal of Gynecological Cancer 2008;18(4):868-75.

\section{Marin 2014}

Marin F, Plesca M, Bordea Cl, Moga MA, Blidaru A. Types of radical hysterectomies: from Thoma lonescu and Wertheim to present day. Journal of Medicine and Life 2014;7(2):172-6.

\section{Maserejian 2014}

Maserejian NN, Chen S, Chiu GR, Araujo AB, Kupelian V, Hall SA et al. Treatment status and progression or regression of lower urinary tract symptoms in a general adult population sample. Journal of Urology 2014;191(1):107-13.

\section{Mota 2008}

Mota F, Vergote I, Trimbos JB, Amant F, Siddiqui N, Del Rio A, et al. Classification of radical hysterectomy adopted by the Gynecological Cancer Group of the European Organization for Research and Treatment of Cancer. International Journal of Gynecological Cancer 2008;18(5):1136-8.

\section{Park 2016 [pers comm]}

Park SY. Asking some information of published article. Email to: parksang@ncc.re.kr 29 October 2016.

\section{Park 2017}

Park DA, Yun JE, Kim SW, Lee SH. Surgical and clinical safety and effectiveness of robot-assisted laparoscopic hysterectomy compared to conventional laparoscopy and laparotomy for cervical cancer: A systematic review and meta-analysis. European Journal of Surgical Oncology 2017;43(6):994-1002.

\section{Parkin 2014}

Parkin DM, Bray F, Ferlay J, Jemal A. Cancer in Africa 2012. Cancer Epidemiology, Biomarkers \& Prevention 2014;23(6):953-66.

\section{Parmar 1998}

Parmar MK, Torri V, Stewart L. Extracting summary statistics to perform meta-analyses of the published literature for survival endpoints. Statistics in Medicine 1998;17(24):2815-34.

\section{Piver 1974}

Piver MS, Rutledge F, Smith JP. Five classes of extended hysterectomy for women with cervical cancer. Obstetrics \& Gynecology 1974;44(2):265-72.

\section{Plotti 2011}

Plotti F, Angioli R, Zullo MA, Sansone M, Altavilla T, Antonelli E, et al. Update on urodynamic bladder dysfunctions after radical hysterectomy for cervical cancer. Critical Reviews in Oncology/ Hematology 2011;80(2):323-9.

\section{Querleu 2008}

Querleu D, Morrow CP. Classification of radical hysterectomy. Lancet Oncology 2008;9(3):297-303.

\section{Ramirez 2018}

Ramireza PT, Frumovitza M, Parejab R, Lopezc A, Vieirad MA, Ribeiro R. Phase III randomized trial of laparoscopic or robotic versus abdominal radical hysterectomy in patients with earlystage cervical cancer: LACC trial. 2018 Society of Gynecologic Oncology Annual Meeting on Women's Cancer. LBA1. Presented March 26, 2018

\section{Review Manager 2014 [Computer program]}

Nordic Cochrane Centre, The Cochrane Collaboration. Review Manager 5 (RevMan 5). Version 5.3. Copenhagen: Nordic Cochrane Centre, The Cochrane Collaboration, 2014.

Nerve-sparing radical hysterectomy compared to standard radical hysterectomy for women with early stage cervical cancer (stage la2 to 


\section{Schünemann 2011}

Schünemann HJ, Oxman AD, Higgins JP, Vist GE, Glasziou P, Guyatt GH. Chapter 11: Presenting results and 'Summary of findings' tables. In: Higgins JP, Green S, editor(s). Cochrane Handbook for Systematic Reviews of Interventions Version 5.1.0 (updated March 2011). The Cochrane Collaboration, 2011. Available from handbook.cochrane.org.

\section{Schünemann 2013}

Schünemann HJ, Tugwell P, Reeves BC, Akl EA, Santesso N, Spencer FA, et al. Non-randomized studies as a source of complementary, sequential or replacement evidence for randomized controlled trials in systematic reviews on the effects of interventions. Research Synthesis Methods 2013;4(1):49-62.

\section{Spirtos 2002}

Spirtos NM, Eisenkop SM, Schlaerth JB, Ballon SC. Laparoscopic radical hysterectomy (type III) with aortic and pelvic lymphadenectomy in patients with stage I cervical cancer: surgical morbidity and intermediate follow-up. American Journal of Obstetrics and Gynecology 2002;187(2):340-8.

\section{Srisomboon 2011}

Srisomboon J, Kietpeerakool C, Suprasert P, Manopanya M, Siriaree S, Charoenkwan K, et al. Survival and prognostic factors comparing stage IB 1 versus stage IB 2 cervical cancer treated with primary radical hysterectomy. Asian Pacific Journal of Cancer Prevention 2011;12(7):1753-6.

\section{Sterne 2011}

Sterne J, Sutton A, Loannidis J, Terrin N, Jones D, Lau J, et al. Recommendations for examining and interpreting funnel plot asymmetry in meta-analyses of randomised controlled trials. BMJ 2011;343:d4002.

\section{Suprasert 2010}

Suprasert P, Srisomboon J, Charoenkwan K, Siriaree S, Cheewakriangkrai C, Kietpeerakool C, et al. Twelve years experience with radical hysterectomy and pelvic lymphadenectomy in early stage cervical cancer. Journal of Obstetrics and Gynaecology 2010;30(3):294-8.

\section{Vale 2010}

Vale $C$. Reducing uncertainties about the effects of chemoradiotherapy for cervical cancer: individual patient data meta-analysis. Cochrane Database of Systematic Reviews 2010, Issue 1. [DOI: 10.1002/14651858.CD008285]

\section{CHARACTERISTICS OF STUDIES}

Characteristics of included studies [ordered by study ID]

\section{van Gent 2016}

van Gent MD, Romijn LM, van Santen KE, Trimbos JB, de Kroon $C D$. Nerve-sparing radical hysterectomy versus conventional radical hysterectomy in early-stage cervical cancer. A systematic review and meta-analysis of survival and quality of life. Maturitas 2016;94:30-8.

\section{Verleye 2009}

Verleye L, Vergote I, Reed N, Ottevanger PB. Quality assurance for radical hysterectomy for cervical cancer: the view of the European Organization for Research and Treatment of CancerGynecological Cancer Group (EORTC-GCG). Annals of Oncology 2009;20(10):1631-8.

\section{von Hippel 2015}

von Hippel PT. The heterogeneity statistic $\mathrm{I}^{2}$ can be biased in small meta-analyses. BMC Medical Research Methodology 2015;14(15):35.

\section{Wan 2014}

Wan X, Wang W, Liu J, Tong T. Estimating the sample mean and standard deviation from the sample size, median, range and/or interquartile range. BMC Medical Research Methodology 2014;14:135.

\section{Webster 2003}

Webster K, Cella D, Yost K. The Functional Assessment of Chronic Illness Therapy (FACIT) Measurement System: properties, applications, and interpretation. Health and Quality of Life Outcomes 2003;1:79.

\section{Xue 2016}

Xue Z, Zhu X, Teng Y. Comparison of nerve-sparing radical hysterectomy and radical hysterectomy: a systematic review and meta-analysis. Cellular Physiology and Biochemistry 2016;38(5):1841-50.

\section{References to other published versions of this review}

\section{Kietpeerakool 2017}

Kietpeerakool C, Aue-aungkul A, Galaal K, Ngamjarus C, Lumbiganon P. Nerve-sparing radical hysterectomy compared to standard radical hysterectomy for women with early stage cervical cancer (stage la2 to Ila). Cochrane Database of Systematic Reviews 2017, Issue 10. [DOI: 10.1002/14651858.CD012828]

\section{Chen 2012}

Methods Study design: two-armed parallel, randomised controlled trial Study setting: University Hospital in People's Republic of China Study duration: April 2007 to March 2008 
Chen 2012 (Continued)

Participants Twenty-five women with FIGO stage Ib1 to lla cervical cancer who received neither neoadjuvant treatment nor radiotherapy and had no clinical bladder dysfunction were randomised to undergo standard radical hysterectomy $(\mathrm{N}=13)$ and nerve-sparing radical hysterectomy $(\mathrm{N}=12)$

\begin{tabular}{|c|c|}
\hline Interventions & $\begin{array}{l}\text { Control group: classical Piver III radical hysterectomy. } \\
\text { Intervention: nerve-sparing radical hysterectomy, as described by Fujii } 2007 \text { and Fujii } 2008 . \\
\text { All procedures were carried out via laparotomy approach }\end{array}$ \\
\hline Outcomes & $\begin{array}{l}\text { - Removal of autonomic nerve within the cardinal ligament }(\mathrm{CL}) \text { during nerve-sparing radical hysterec- } \\
\text { tomy (NSRH) compared with radical hysterectomy }(\mathrm{RH}) \text {; } \\
\text { - Postoperative functions of bowel and bladder, such as time to first flatus, time to defecation and time } \\
\text { to postvoid residual urine volume (PVR) } \leq 50 \mathrm{~mL} \text {; and } \\
\text { - Two-year disease-free survival. }\end{array}$ \\
\hline
\end{tabular}

\section{Notes}

\section{Risk of bias}

\begin{tabular}{|c|c|c|}
\hline Bias & Authors' judgement & Support for judgement \\
\hline $\begin{array}{l}\text { Random sequence genera- } \\
\text { tion (selection bias) }\end{array}$ & Unclear risk & No statement regarding the method used to generate the allocation sequence \\
\hline $\begin{array}{l}\text { Allocation concealment } \\
\text { (selection bias) }\end{array}$ & Unclear risk & No statement regarding the method used to conceal the allocation sequence \\
\hline $\begin{array}{l}\text { Blinding of participants } \\
\text { and personnel (perfor- } \\
\text { mance bias) } \\
\text { All outcomes }\end{array}$ & Unclear risk & No statement regarding the blinding of participants and personnel \\
\hline
\end{tabular}

\begin{tabular}{lll}
$\begin{array}{l}\text { Blinding of outcome as- } \\
\text { sessment (detection bias) } \\
\text { All outcomes }\end{array}$ & Unclear risk & No statement regarding the blinding of outcome assessment \\
\hline $\begin{array}{l}\text { Incomplete outcome data } \\
\text { (attrition bias) }\end{array}$ & Low risk & $\begin{array}{l}\text { Of } 25 \text { participants randomised, two participants lost to follow-up, (one partic- } \\
\text { ipant assigned in each of two comparison groups), corresponding to a rate of } \\
\text { incomplete outcome data of approximately 8\%, thus this is unlikely to influ- } \\
\text { ence the effect of treatment assigned }\end{array}$
\end{tabular}

\begin{tabular}{|c|c|c|}
\hline $\begin{array}{l}\text { Selective reporting (re- } \\
\text { porting bias) }\end{array}$ & High risk & $\begin{array}{l}\text { The reported 2-year DFS in this study is considered to be too short for deter- } \\
\text { mining survival outcome of women with early stage cervical cancer. No infor- } \\
\text { mation on perioperative complication was reported }\end{array}$ \\
\hline Other bias & Unclear risk & $\begin{array}{l}\text { Information was insufficient for assessment of whether an important risk of } \\
\text { bias existed. }\end{array}$ \\
\hline
\end{tabular}

\section{Chen 2014}

Study design: two-armed parallel, randomised controlled trial
Study setting: University Hospital in People's Republic of China
Study duration: March 2010 to March 2014


Chen 2014 (Continued)

Participants Participants were 65 women with stage la2 to $\mathbb{I a} 2$ cervical cancer (35 in nerve-sparing group and 30 in standard operation group). Exclusion criteria included a history of voiding dysfunction, previous pelvic radiotherapy, previous pelvic reconstruction, and brain/spinal cord diseases.

Control: Querleu and Morrow type C, standard laparoscopic radical hysterectomy
Intervention: Querleu and Morrow type C, nerve-sparing laparoscopic radical hysterectomy
All women received cisplatin-based adjuvant chemotherapy in 1-2 courses before surgery depending
on tolerance and response.

\begin{tabular}{ll}
\hline Outcomes & Perioperative outcomes including blood loss, operative time, complications \\
- Bladder functions (duration of the postoperative catheterisation, maximum flow rate (MFR), maxi- \\
mum detrusor pressure (MDP) evaluated by urodynamic study at 6 to 12 months following operation. \\
- Intestinal functions and urinary symptoms assessed by a questionnaire at 1 year after the operation. \\
- Quality of sexual life assessed by Female Sexual Function Index (FSFI) at 1 year after the operation. \\
\hline Notes
\end{tabular}

\section{Risk of bias}

\begin{tabular}{|c|c|c|}
\hline Bias & Authors' judgement & Support for judgement \\
\hline $\begin{array}{l}\text { Random sequence genera- } \\
\text { tion (selection bias) }\end{array}$ & Unclear risk & No statement regarding the method used to generate the allocation sequence \\
\hline $\begin{array}{l}\text { Allocation concealment } \\
\text { (selection bias) }\end{array}$ & Unclear risk & No statement regarding the method used to conceal the allocation sequence \\
\hline $\begin{array}{l}\text { Blinding of participants } \\
\text { and personnel (perfor- } \\
\text { mance bias) } \\
\text { All outcomes }\end{array}$ & Unclear risk & $\begin{array}{l}\text { No statement regarding the blinding of participants and personnel. Some out- } \\
\text { comes such as postoperative urinary symptoms and quality of sexual life as- } \\
\text { sessed by a questionnaire are likely to be influence by lack of blinding }\end{array}$ \\
\hline $\begin{array}{l}\text { Blinding of outcome as- } \\
\text { sessment (detection bias) } \\
\text { All outcomes }\end{array}$ & Unclear risk & No statement regarding the blinding of outcome assessment \\
\hline $\begin{array}{l}\text { Incomplete outcome data } \\
\text { (attrition bias) } \\
\text { All outcomes }\end{array}$ & High risk & $\begin{array}{l}\text { Only } 16 \text { women participants ( } 24.6 \%) \text { in both arms underwent urodynamic } \\
\text { study to evaluate postoperative bladder functions ( } 7 \text { or } 23.3 \% \text { in nerve-sparing } \\
\text { group and } 9 \text { or } 25.7 \% \text { in standard surgery group), which was one of the prima- } \\
\text { ry outcomes of interest in this study }\end{array}$ \\
\hline $\begin{array}{l}\text { Selective reporting (re- } \\
\text { porting bias) }\end{array}$ & Low risk & All potential relevant outcomes were reported \\
\hline Other bias & Unclear risk & $\begin{array}{l}\text { Information was insufficient for assessment of whether an important risk of } \\
\text { bias existed. }\end{array}$ \\
\hline
\end{tabular}

\section{Roh 2015}

Study design:two-armed parallel, randomised controlled trial
Study setting: multicentre, two-armed parallel, randomised controlled trial conducted in University
Hospitals and Tertiary Hospital in Korea

Nerve-sparing radical hysterectomy compared to standard radical hysterectomy for women with early stage cervical cancer (stage la2 to 
Roh 2015 (Continued)

Study duration: March 2003 to November 2005

Participants

Ninety-two women with cervical cancer stage IA2 to IIA were randomly assigned for surgical treatment with standard radical hysterectomy or nerve-sparing radical hysterectomy, and 86 women were finally included in the analysis.

Exclusion criteria were neuroendocrine histology, pathologically proven distant metastasis, history of psychiatric disease, preoperative urinary dysfunction, and another coexisting malignancy. Women with an adequate follow-up duration of more than one year after the surgery were included in the analysis ( 86 women; 40 in standard surgery and 46 in nerve-sparing surgery)

Control group: classical Piver III radical hysterectomy ()
Intervention group: nerve-sparing radical hysterectomy
All procedures were carried out via laparotomy approach.
$\begin{aligned} & \text { Type of radical hysterectomy was additionally provided by contact author of this study (Park } 2016 \text { [pers } \\ & \text { comm]) }\end{aligned}$

Outcomes

Bladder function recovery: time to postvoid residual urinary volume (PVR) $<50 \mathrm{~mL}$ and bladder function (PVR, maximal urethral closure pressure (MUCP), maximum flow rate (MFR), average flow rate (AFR), bladder compliance, and detrusor pressure at maximum flow) assessed by urodynamic study performed at 1, 3, and 12 months following operation;

Subjective urinary symptoms using International Prostate Symptom Score (IPPS);

Ten-year disease-free and overall survival.

\section{Notes}

The analyses performed in this study was not based on an intention-to-treat basis as only participants with follow-up duration of more than one year after surgery were included in the final analyses. Estimation of disease-free survival was based unadjusted hazard ratio.

\section{Risk of bias}

\begin{tabular}{lll}
\hline Bias & Authors' judgement & Support for judgement \\
\hline $\begin{array}{l}\text { Random sequence genera- } \\
\text { tion (selection bias) }\end{array}$ & Unclear risk & No statement regarding the method used to generate the allocation sequence \\
\hline $\begin{array}{l}\text { Allocation concealment } \\
\text { (selection bias) }\end{array}$ & Unclear risk & No statement regarding the method used to conceal the allocation sequence \\
\hline $\begin{array}{l}\text { Blinding of participants } \\
\text { and personnel (perfor- } \\
\text { mance bias) }\end{array}$ & Unclear risk & $\begin{array}{l}\text { No statement regarding the blinding of participants and personnel. Some out- } \\
\text { comes such as subjective bladder dysfunction assessed by a questionnaire is } \\
\text { likely to be influence by lack of blinding }\end{array}$ \\
\hline $\begin{array}{l}\text { Blinding of outcome as- } \\
\text { sessment (detection bias) } \\
\text { All outcomes }\end{array}$ & Unclear risk & $\begin{array}{l}\text { The authors stated that there was one urologist responsible for assessing the } \\
\text { results of urodynamic study without any clinical information, but further de- } \\
\text { scription of blinding is not included }\end{array}$ \\
\hline $\begin{array}{l}\text { Incomplete outcome data } \\
\text { (attrition bias) } \\
\text { All outcomes }\end{array}$ & Low risk & $\begin{array}{l}\text { Of 92 participants randomised, four participants lost to follow-up (2) or discon- } \\
\text { tinued intervention (2), corresponding to a rate of incomplete outcome data of } \\
\text { approximately 4.3\% thus this is unlikely to influence the effect of treatment as- } \\
\text { signed }\end{array}$ \\
\hline
\end{tabular}

$\begin{aligned} & \text { Selective reporting (re- Low risk } \quad \text { All potential relevant outcomes were reported } \\ & \text { porting bias) }\end{aligned}$

Nerve-sparing radical hysterectomy compared to standard radical hysterectomy for women with early stage cervical cancer (stage la2 to 
Roh 2015 (Continued)

Other bias
High risk
The analyses performed in this study was not based on an intention-to-treat basis.

Wu 2010

\begin{tabular}{|c|c|}
\hline Methods & $\begin{array}{l}\text { Study design: two-armed parallel, randomised controlled trial } \\
\text { Study setting: University Hospital in People's Republic of China } \\
\text { Study duration: March } 2007 \text { to July } 2008\end{array}$ \\
\hline Participants & $\begin{array}{l}\text { Thirty-one women with (FIGO) stages IB1 to IIA cervical cancer were randomly to undergo standard rad- } \\
\text { ical hysterectomy }(\mathrm{N}=15) \text { and nerve-sparing radical hysterectomy }(\mathrm{N}=16) \text {. All participants had no ob- } \\
\text { vious abnormal bladder function prior to operation determined by urodynamic study. However, only } 29 \\
\text { women completed the study and included in the analysis. }\end{array}$ \\
\hline Interventions & $\begin{array}{l}\text { Control group: classical Piver III radical hysterectomy. } \\
\text { Intervention: nerve-sparing radical hysterectomy, as described by Fujii 2007; and Fujii } 2008 \\
\text { All procedures were carried out via laparotomy approach }\end{array}$ \\
\hline Outcomes & $\begin{array}{l}\text { - Major postoperative complications including intestinal obstruction, urinary tract injury, deep vein } \\
\text { thrombosis, lymphocyst formation, fever, and poor wound healing } \\
\text { - Bladder function recovery: time to postvoid residual urinary volume (PVR) }<100 \mathrm{~mL} \text { and bladder func- } \\
\text { tion (PVR, MUCP, MFR, average flow rate (AFR), bladder compliance, and stress incontinence) assessed } \\
\text { by urodynamic study at } 6 \text { to } 12 \text { months following operation. } \\
\text { - Perioperative outcomes including operative time and amount of blood loss } \\
\text { - Quality of life evaluated by Functional Assessment of Cervical Cancer Therapy (FACT-CX) }\end{array}$ \\
\hline
\end{tabular}

Notes

Information was insufficient for assessment of whether an important risk of bias existed.

\section{Risk of bias}

\begin{tabular}{lll} 
Bias & Authors' judgement & Support for judgement \\
\hline $\begin{array}{l}\text { Random sequence genera- } \\
\text { tion (selection bias) }\end{array}$ & Unclear risk & No statement regarding the method used to generate the allocation sequence \\
\hline $\begin{array}{l}\text { Allocation concealment } \\
\text { (selection bias) }\end{array}$ & Unclear risk & No statement regarding the method used to conceal the allocation sequence \\
\hline $\begin{array}{l}\text { Blinding of participants } \\
\text { and personnel (perfor- } \\
\text { mance bias) }\end{array}$ & Unclear risk & $\begin{array}{l}\text { No statement regarding the blinding of participants and personnel. Some out- } \\
\text { comes such as quality of life is likely to be influence by lack of blinding }\end{array}$ \\
\hline
\end{tabular}

\begin{tabular}{|c|c|c|}
\hline $\begin{array}{l}\text { Blinding of outcome as- } \\
\text { sessment (detection bias) }\end{array}$ & Unclear risk & $\begin{array}{l}\text { The authors stated that participants were assessed blindly by a direct program } \\
\text { control (DPC), but further description of blinding is not included }\end{array}$ \\
\hline
\end{tabular}

Incomplete outcome data Low risk All participants were analysed for all outcomes. No missing data
(attrition bias)
All outcomes


Wu 2010 (Continued)

Selective reporting (re- Low risk All potential relevant outcomes were reported
porting bias)

Other bias

Unclear risk

Information was insufficient for assessment of whether an important risk of bias existed.

DFS: disease-free survival FIGO: Federation of Gynecology and Obstetrics

Characteristics of excluded studies [ordered by study ID]

\begin{tabular}{ll}
\hline Study & Reason for exclusion \\
\hline
\end{tabular}

Barbic $2012 \quad$ Non-randomised study

Details: this retrospective study was conducted to assess the amount of nerves in the removed parametrial tissue. Histological specimens from nerve-sparing radical hysterectomy (28 cases) were compared with those obtained after classic radical hysterectomy ( 26 cases).

\section{Bogani 2014}

\section{Non-randomised study}

Deatils: this retrospective non-randomised study was conducted to determine the perioperative outcomes and survivals of women with cervical cancer stage la2-IIb undergoing laparoscopic radical hysterectomy. Thirty-three and 63 women had undergone laparoscopic nerve-sparing radical hysterectomy and conventional laparoscopic radical hysterectomy, respectively.

\section{Review article}

Detials: this reference is a review article describing the surgical steps for parametrial dissection during laparoscopic nerve-sparing radical hysterectomy.

\section{Ceccaroni $2012 \quad$ Non-randomised study}

Details: the objective of this multicentre retrospective study was to compare standard radical hysterectomy with nerve-sparing radical hysterectomy with regards to postoperative pelvic dysfunctions, clinical outcome, survival and quality of life. A total of 56 women were included; 31 underwent standard radical hysterectomy and 25 nerve-sparing radical hysterectomy.

\section{Non-randomised study}

Details: the objective of this reference was to describe the surgical techniques of nerve-sparing type III radical hysterectomy. Perioperative outcomes of 22 women with cervical cancer undergoing nerve-sparing type III radical hysterectomy were compared to the women who had undergone standard radical hysterectomy performed at the author's institution.

\section{Cibula $2010 \quad$ Non-randomised study}

Details: this prospective non-randomised study was conducted to assess the morbidity of women with early stage cervical cancer before and 6 months following nerve-sparing radical hysterectomy compared to that with the morbidity in women following different types of parametrectomy without nerve sparing.

\section{Ditto $2009 \quad$ Non-randomised study}

Details: this is an observational cross-sectional study conducted to evaluate quality of life and bladder, intestinal, and sexual dysfunctions in 2 groups of women undergoing class II radical hysterectomy and group 2, class III nerve-sparing radical hysterectomy.

Hockel $2000 \quad$ Non-randomised study




\begin{tabular}{ll}
\hline Study & Reason for exclusion \\
\hline Details: this is a case-control study assessing outcomes of women undergoing nerve-sparing radi- \\
cal hysterectomy $(\mathrm{N}=41)$ compared to 139 women following standard radical hysterectomy.
\end{tabular}

\section{Kanao 2014}

\section{Non-randomised study}

Details: this study assessed the correlation between preserved pelvic nerve networks and bladder function after laparoscopic nerve-sparing radical hysterectomy. All women had undergone laparoscopic nerve-sparing radical hysterectomy and were further classified into three groups depending on the status of preserved pelvic nerve networks: complete preservation of the pelvic nerve plexus (group A, 27 cases); partial preservation (group B, 13 cases); and complete sacrifice (group C, 13 cases).

\section{Kim $2017 \quad$ Non-randomised study}

Details: this non-randomised study prospectively assessed 87 consecutive women with IB1-IIA cervical cancer who underwent nerve-sparing radical hysterectomy. Information of 81 women who received standard radical hysterectomy were reviewed for historical comparisons. The objectives of this study are to investigate favourable factors of nerve-sparing radical hysterectomy (NSRH) for preserving the pelvic autonomic nerves and subsequent bladder function and to compare the safety between nerve-sparing radical hysterectomy and standard radical hysterectomy.

\section{Milani $1991 \quad$ Wrong comparator}

Details: this randomised study was conducted to evaluate the impact of two types of hysterectomy (type II hysterectomy versus type III hysterectomy) on the bladder functions among 31 women with Ib to lla cervical cancer.

\section{Querleu $2002 \quad$ Non-randomised study}

Details: this retrospective study was conducted to determine the outcome of women undergoing laparoscopically-assisted modified radical hysterectomy, with or without paracervical dissection.

\section{Non-randomised study}

Details: this is a retrospective study assessing 110 women with histologically diagnosed cervical cancer treated surgically with type II or III radical hysterectomy with or without nerve-sparing approach.

\section{Raspagliesi 2017}

\section{Non-randomised study}

Details: this is a retrospective, non-randomised study conducted to assess the impact of nervesparing approach on outcomes of women undergoing minimally invasive radical hysterectomy for locally advanced stage cervical cancer. All women included had minimally invasive class III radical hysterectomy.

\section{An editorial article}

Details: this is an editorial article for the randomised controlled trial published in Journal of Gynecologic Oncology (Efficacy and oncologic safety of nerve-sparing radical hysterectomy for cervical cancer: a randomized controlled trial. Journal of Gynecologic Oncology 2015; 26(2); 90).

\section{Shi 2016}

\section{Non-randomised study}

Details: this is a retrospective study which was undertaken to assess perioperative and postoperative outcomes compared between women with biopsy-proven, early-stage cervical carcinoma underwent with laparoscopic nerve-sparing radical hysterectomy $(N=64)$ versus those treated with standard laparoscopic radical hysterectomy $(\mathrm{N}=42)$.

\section{Skret-Magierlo $2010 \quad$ Non-randomised study}




\begin{tabular}{ll}
\hline Study & Reason for exclusion \\
\hline Details: the aim of this non-randomised study was to compare peri- and postoperative outcomes of \\
20 women with cervical cancer operated on using the new nerve-sparing technique of radical hys- \\
terectomy with data gathered from those who underwent traditional radical hysterectomy.
\end{tabular}

Su $2017 \quad$ Non-randomised study

Details: the aim of this non-randomised study was to assess the impact of nerve-sparing approach on the postoperative rectal function among women with IB to IIA cervical cancer, compared with standard radical hysterectomy.

\section{Todo $2006 \quad$ Non-randomised study}

Details: the objective of this non-randomised study was to assess the postsurgical bladder function by urodynamic study in 27 women with cervical cancer treated with nerve-sparing radical hysterectomy. All women were further classified into 2 groups depending on the completion of preservation of the autonomic nerves. Autonomic nerves had been completely preserved at least on one side in 22 women and autonomic nerves could not be successfully preserved in the remaining five women.

\section{Tseng $2012 \quad$ Non-randomised study}

Details: the objective of this prospective non-randomised study was to determine the lower urinary tract function among women with cervical carcinoma stage la2 to lb1 who underwent either nervesparing radical hysterectomy or standard radical hysterectomy at a tertiary referral hospital in Taiwan.

\section{Non-randomised study}

Details: this non-randomised study assessed the outcomes of laparoscopic nerve-sparing radical hysterectomy for bulky stage cervical cancer (lesion $6 \mathrm{~cm}$ ) after neoadjuvant chemotherapy compared to those who underwent standard laparoscopic radical hysterectomy.

\section{Characteristics of ongoing studies [ordered by study ID]}

Gaballa 2015

$\begin{array}{ll}\text { Trial name or title } & \begin{array}{l}\text { Feasibility and functional outcome of laparoscopic nerve sparing radical hysterectomy } \\ \text { (NCT02524756) }\end{array}\end{array}$

Methods Study type: interventional study

Study design: phase III randomised controlled trial

Intervention model: parallel assignment

Masking: no masking

Primary purpose: treatment outcome measures

Participants' characteristics: women aged 18 years or over
Inclusion criteria
- Age $>18$ years
- Karnofsky > 80, or American Society of Anaethesiology (ASA) I-II
- Stage IA2-IB1-IB2-IIA1-IIA2-IIB cervical cancer according to FIGO (International Federation of Gy-
- necology and Obstetrics) staging
Exclusion criteria
- Non-invasive cancer
- Pregnancy

Nerve-sparing radical hysterectomy compared to standard radical hysterectomy for women with early stage cervical cancer (stage la2 to 
Gaballa 2015 (Continued)

- Bladder dysfunction detected prior to surgery

- Previous pelvic lymphadenectomy

- Tumour recurrence

- Incomplete surgery, unresectable lesion

Interventions Intervention: laparoscopic nerve-sparing radical hysterectomy (type III/C1)

Control: laparoscopic radical hysterectomy (type III/C2).

Outcomes Primary outcome measures: duration of postoperative catheterisation until PVR urine volume is less than $100 \mathrm{~mL}$

Secondary outcome measures: intraoperative complications, amount of blood intraoperative blood loss, operative time, occurrence of early postoperative complication within 30 days of operation, occurrence of late complications related to surgery more than 30 days postoperative Removal of urinary catheter on the third day postoperative without prior bladder training exercise and measurement of PVR

\begin{tabular}{ll}
\hline Starting date & November 2014 \\
\hline Contact information & Principal Investigator: Khaled Gaballa, Assistant Lecturer of surgical oncology, Mansoura Universit- \\
ry & $\begin{array}{l}\text { Study Chair: Adel Taha Denewar, MD, Ph.D, Head of surgical oncology department, Mansoura on- } \\
\text { cology centre, Mansoura University } \\
\text { Study Director: Giovanni Scambia, MD,Ph.D, Head of the Department for Woman and Unborn Life } \\
\text { Health Care- Catholic University of the Sacred Heart- Rome, Italy }\end{array}$ \\
\hline Notes & ClinicalTrials.gov Identifier: NCT02524756 \\
\hline
\end{tabular}

PVR: postvoid residual urine volume

\section{DATA AND ANALYSES}

Comparison 1. Postvoid residual volume of urine measured after operation

\begin{tabular}{|c|c|c|c|c|}
\hline Outcome or subgroup title & No. of studies & $\begin{array}{l}\text { No. of partici- } \\
\text { pants }\end{array}$ & Statistical method & Effect size \\
\hline $\begin{array}{l}1 \text { Time to postvoid residual volume of } \\
\text { urine } \leq 50 \mathrm{~mL}\end{array}$ & 2 & 111 & $\begin{array}{l}\text { Mean Difference (IV, Ran- } \\
\text { dom, } 95 \% \mathrm{CI})\end{array}$ & $\begin{array}{l}-13.21[-24.02 \\
-2.41]\end{array}$ \\
\hline $\begin{array}{l}2 \text { Time to postvoid residual volume of } \\
\text { urine } \leq 100 \mathrm{~mL}\end{array}$ & 2 & 58 & $\begin{array}{l}\text { Mean Difference (IV, Ran- } \\
\text { dom, } 95 \% \mathrm{CI} \text { ) }\end{array}$ & $\begin{array}{l}-9.59[-16.28 \\
-2.90]\end{array}$ \\
\hline $\begin{array}{l}3 \text { Postvoid residual volume of urine at } 1 \\
\text { month after operation }\end{array}$ & 1 & & $\begin{array}{l}\text { Mean Difference (IV, Ran- } \\
\text { dom, } 95 \% \mathrm{CI} \text { ) }\end{array}$ & Subtotals only \\
\hline $\begin{array}{l}4 \text { Postvoid residual volume of urine at } 3 \\
\text { months after operation }\end{array}$ & 1 & & $\begin{array}{l}\text { Mean Difference (IV, Ran- } \\
\text { dom, } 95 \% \mathrm{CI})\end{array}$ & Subtotals only \\
\hline $\begin{array}{l}5 \text { Postvoid residual volume of urine at } 12 \\
\text { months after operation }\end{array}$ & 1 & & $\begin{array}{l}\text { Mean Difference (IV, Ran- } \\
\text { dom, } 95 \% \mathrm{CI} \text { ) }\end{array}$ & Subtotals only \\
\hline
\end{tabular}


Analysis 1.1. Comparison 1 Postvoid residual volume of urine measured after operation, Outcome 1 Time to postvoid residual volume of urine $\leq 50 \mathrm{~mL}$.

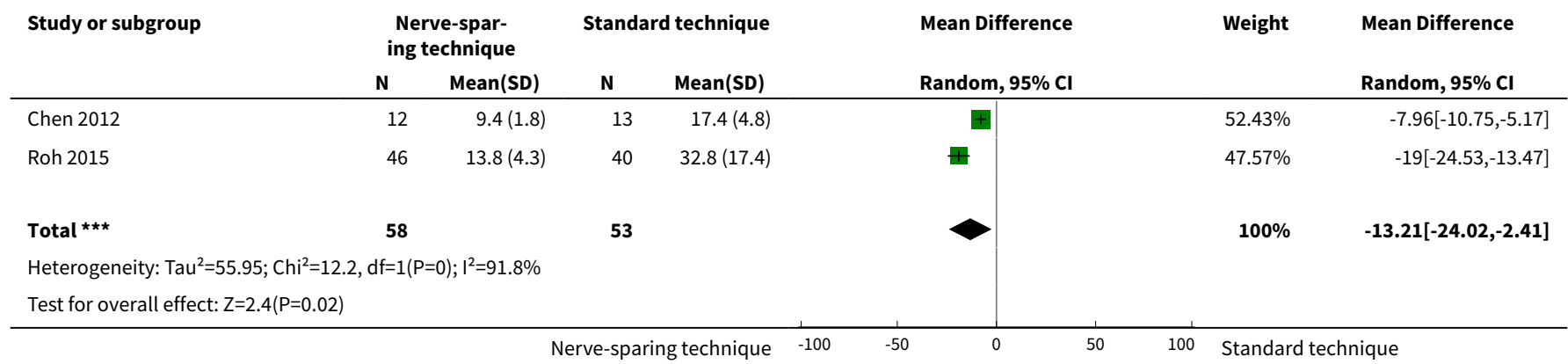

Analysis 1.2. Comparison 1 Postvoid residual volume of urine measured after operation, Outcome 2 Time to postvoid residual volume of urine $\leq 100 \mathrm{~mL}$.

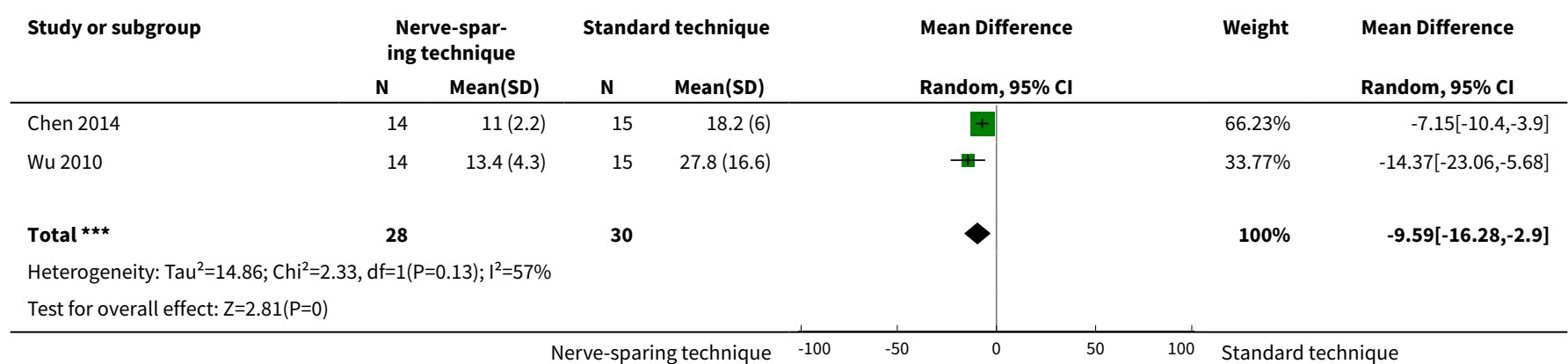

Analysis 1.3. Comparison 1 Postvoid residual volume of urine measured after operation, Outcome 3 Postvoid residual volume of urine at 1 month after operation.

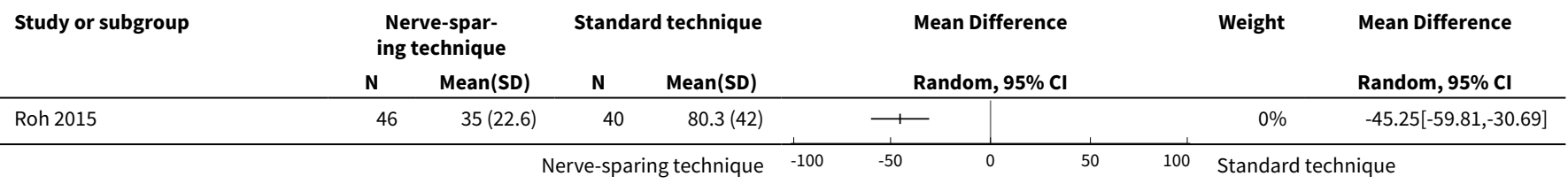

Analysis 1.4. Comparison 1 Postvoid residual volume of urine measured after operation, Outcome 4 Postvoid residual volume of urine at 3 months after operation.

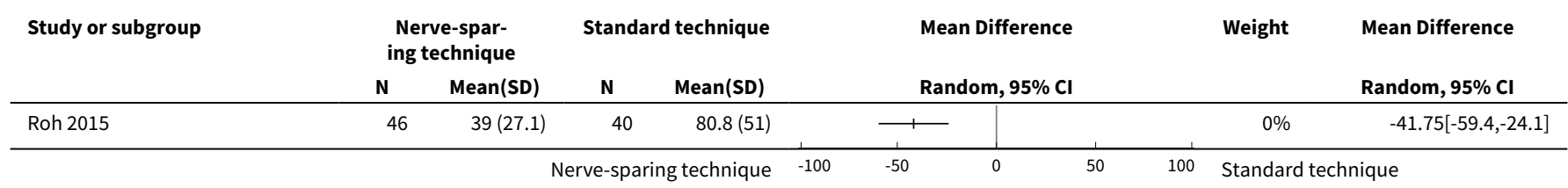


Analysis 1.5. Comparison 1 Postvoid residual volume of urine measured after operation, Outcome 5 Postvoid residual volume of urine at 12 months after operation.

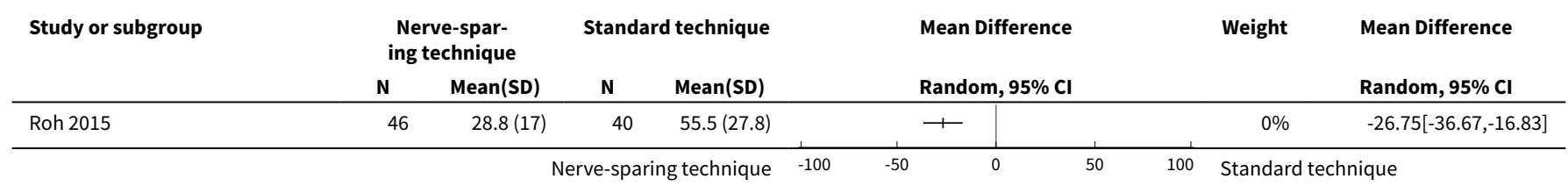

\section{Comparison 2. Adverse events (excluding bladder dysfunction)}

\begin{tabular}{lllll}
\hline Outcome or subgroup title & No. of studies & $\begin{array}{l}\text { No. of partici- } \\
\text { pants }\end{array}$ & Statistical method & Effect size \\
\hline 1 Perioperative complication & 3 & 180 & $\begin{array}{l}\text { Risk Ratio (IV, Random, 95\% } \\
\text { Cl) }\end{array}$ & $0.55[0.24,1.26]$ \\
\hline
\end{tabular}

Analysis 2.1. Comparison 2 Adverse events (excluding bladder dysfunction), Outcome 1 Perioperative complication.

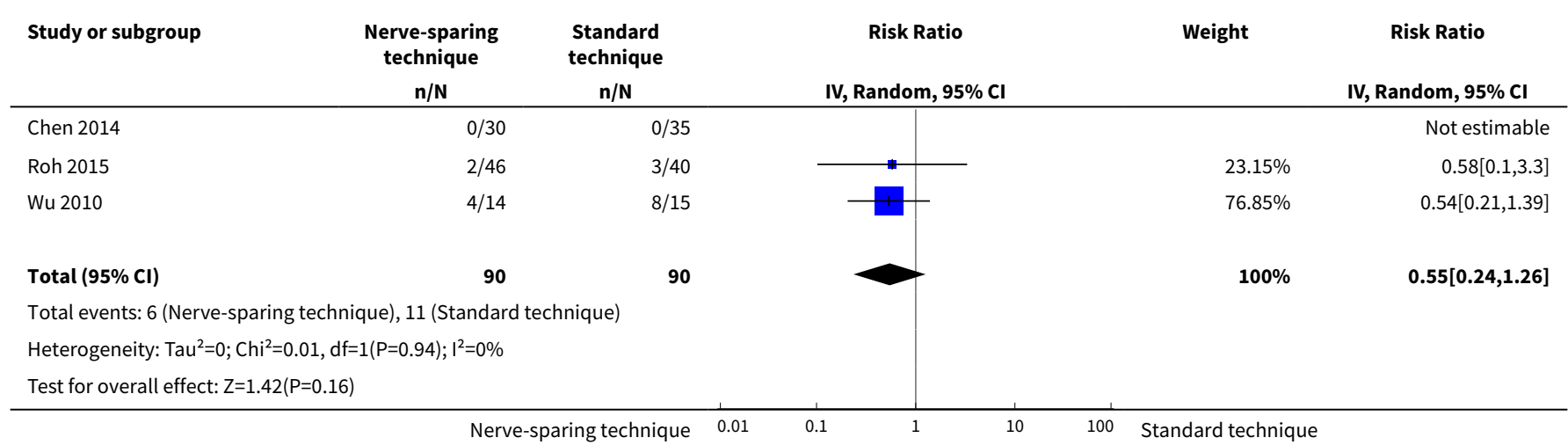

Comparison 3. Subjective urinary symptoms

\begin{tabular}{llllc}
\hline Outcome or subgroup title & No. of studies & $\begin{array}{l}\text { No. of partici- } \\
\text { pants }\end{array}$ & Statistical method & Effect size \\
\hline $\begin{array}{l}\text { 1 Subjective urinary symptoms at } 1 \\
\text { months after operation }\end{array}$ & 1 & $\begin{array}{l}\text { Mean Difference (IV, Ran- } \\
\text { dom, 95\% CI) }\end{array}$ & Subtotals only \\
\hline $\begin{array}{l}\text { 2 Subjective urinary symptoms at } 3 \\
\text { months after operation }\end{array}$ & 1 & $\begin{array}{l}\text { Mean Difference (IV, Ran- } \\
\text { dom, 95\% CI) }\end{array}$ & Subtotals only \\
\hline $\begin{array}{l}\text { 3 Subjective urinary symptoms at } 6 \\
\text { months after operation }\end{array}$ & 1 & $\begin{array}{l}\text { Mean Difference (IV, Ran- } \\
\text { dom, 95\% CI) }\end{array}$ & Subtotals only \\
\hline
\end{tabular}

Nerve-sparing radical hysterectomy compared to standard radical hysterectomy for women with early stage cervical cancer (stage la2 to 
Analysis 3.1. Comparison 3 Subjective urinary symptoms, Outcome 1 Subjective urinary symptoms at 1 months after operation.

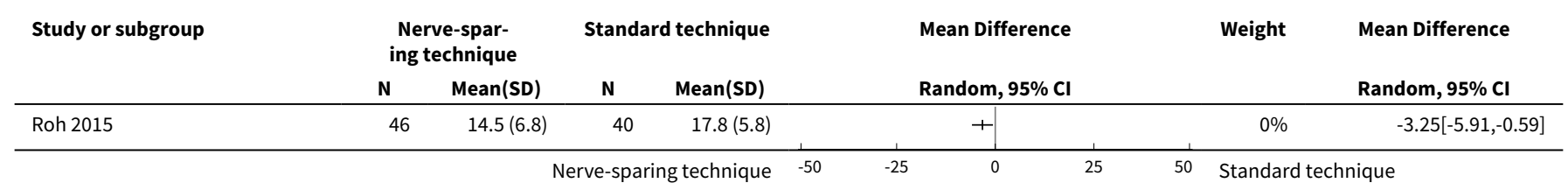

Analysis 3.2. Comparison 3 Subjective urinary symptoms, Outcome 2 Subjective urinary symptoms at 3 months after operation.

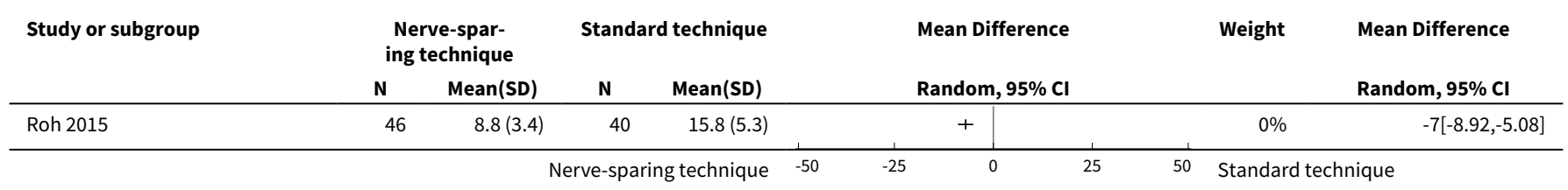

Analysis 3.3. Comparison 3 Subjective urinary symptoms, Outcome 3 Subjective urinary symptoms at 6 months after operation.

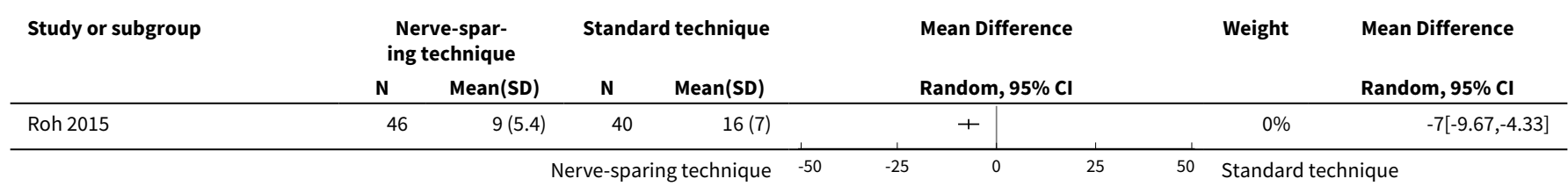

\section{Comparison 4. Disease-free survival}

\begin{tabular}{lllll}
\hline Outcome or subgroup title & No. of studies & $\begin{array}{l}\text { No. of partici- } \\
\text { pants }\end{array}$ & Statistical method & Effect size \\
\hline 1 Disease-free survival & 1 & Hazard Ratio (Random, 95\% Cl) & Subtotals only \\
\hline
\end{tabular}

Analysis 4.1. Comparison 4 Disease-free survival, Outcome 1 Disease-free survival.

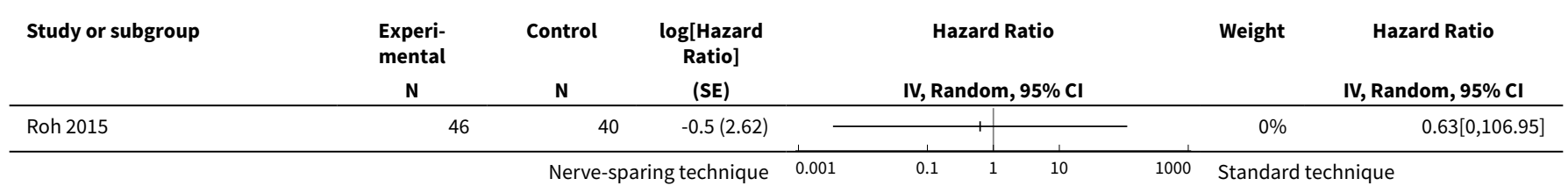




\section{Comparison 5. Cancer recurrence}

\begin{tabular}{lllll}
\hline Outcome or subgroup title & No. of studies & $\begin{array}{l}\text { No. of partici- } \\
\text { pants }\end{array}$ & Statistical method & Effect size \\
\hline 1 Rate of cancer recurrence & 2 & 111 & Risk Ratio (IV, Random, 95\% Cl) & $1.62[0.35,7.38]$ \\
\hline
\end{tabular}

Analysis 5.1. Comparison 5 Cancer recurrence, Outcome 1 Rate of cancer recurrence.

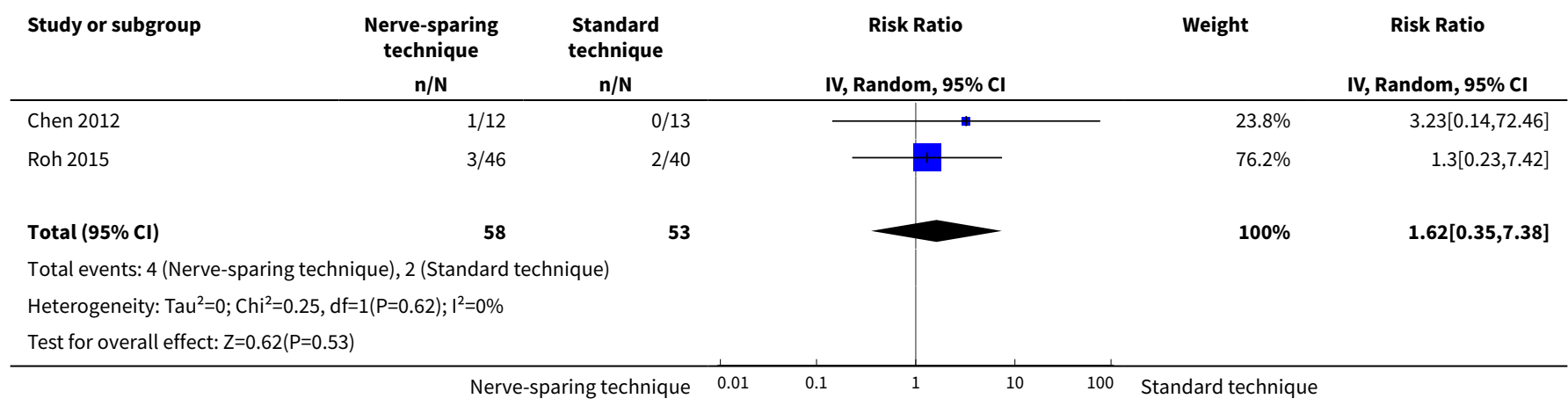

Comparison 6. Maximal urethral closure pressure $\left(\mathrm{cmH}_{2} \mathrm{O}\right)$

\begin{tabular}{lllll}
\hline Outcome or subgroup title & No. of studies & $\begin{array}{l}\text { No. of partici- } \\
\text { pants }\end{array}$ & Statistical method & Effect size \\
\hline $\begin{array}{l}1 \text { Maximal urethral closure pressure }\left(\mathrm{cmH}_{2} \mathrm{O}\right) \\
\text { by urodynamic study at 1 month after opera- } \\
\text { tion }\end{array}$ & 1 & & $\begin{array}{l}\text { Mean Difference (IV, } \\
\text { Random, 95\% Cl) }\end{array}$ & Subtotals only \\
\hline $\begin{array}{l}\text { 2 Maximal urethral closure pressure }\left(\mathrm{cmH}_{2} \mathrm{O}\right) \\
\text { by urodynamic study at 6-12 months after op- } \\
\text { eration }\end{array}$ & 2 & 115 & Mean Difference (IV, & $14.26[5.57$, \\
\hline
\end{tabular}

Analysis 6.1. Comparison 6 Maximal urethral closure pressure $\left(\mathrm{cmH}_{2} \mathrm{O}\right)$, Outcome 1 Maximal urethral closure pressure $\left(\mathrm{cmH}_{2} \mathrm{O}\right)$ by urodynamic study at 1 month after operation.

\begin{tabular}{|c|c|c|c|c|c|c|c|c|c|c|}
\hline \multirow[t]{2}{*}{ Study or subgroup } & \multicolumn{2}{|c|}{$\begin{array}{l}\text { Nerve-spar- } \\
\text { ing technique }\end{array}$} & \multicolumn{2}{|c|}{ Standard technique } & \multirow{2}{*}{\multicolumn{3}{|c|}{$\begin{array}{l}\text { Mean Difference } \\
\text { Random, } 95 \% \mathrm{Cl}\end{array}$}} & \multirow{3}{*}{\multicolumn{2}{|c|}{$\begin{array}{r}\text { Weight } \\
0 \%\end{array}$}} & \multirow{2}{*}{$\begin{array}{l}\text { Mean Difference } \\
\text { Random, } 95 \% \mathrm{Cl}\end{array}$} \\
\hline & $\mathbf{N}$ & Mean(SD) & $\mathbf{N}$ & $\operatorname{Mean}(S D)$ & & & & & & \\
\hline Roh 2015 & 46 & $90.3(23.7)$ & 40 & $76.1(20.4)$ & & & + & & & $14.2[4.87,23.53]$ \\
\hline
\end{tabular}


Analysis 6.2. Comparison 6 Maximal urethral closure pressure $\left(\mathrm{cmH}_{2} \mathrm{O}\right)$, Outcome 2 Maximal urethral closure pressure $\left(\mathrm{cmH}_{2} \mathrm{O}\right)$ by urodynamic study at 6-12 months after operation.

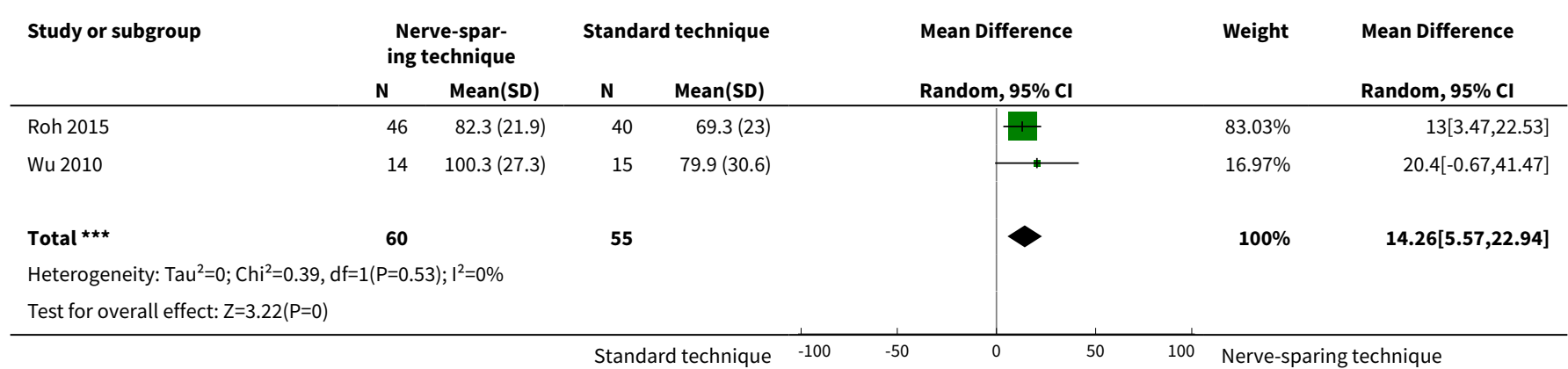

\section{Comparison 7. Flow rate ( $\mathrm{mL}$ per second)}

\begin{tabular}{lllll}
\hline Outcome or subgroup title & No. of studies & $\begin{array}{l}\text { No. of partici- } \\
\text { pants }\end{array}$ & Statistical method & Effect size \\
\hline $\begin{array}{l}1 \text { Maximum flow rate }(\mathrm{mL} \text { per second) at } 1 \\
\text { month after operation }\end{array}$ & 1 & & $\begin{array}{l}\text { Mean Difference (IV, Ran- } \\
\text { dom, 95\% Cl) }\end{array}$ & Subtotals only \\
\hline $\begin{array}{l}\text { 2 Maximum flow rate (mL per second) at } \\
\text { 6-12 months after operation }\end{array}$ & 3 & 131 & $\begin{array}{l}\text { Mean Difference (IV, Ran- } \\
\text { dom, 95\% Cl) }\end{array}$ & $6.39[4.68,8.11]$ \\
\hline
\end{tabular}

Analysis 7.1. Comparison 7 Flow rate ( $\mathrm{mL}$ per second), Outcome

1 Maximum flow rate ( $\mathrm{mL}$ per second) at 1 month after operation.

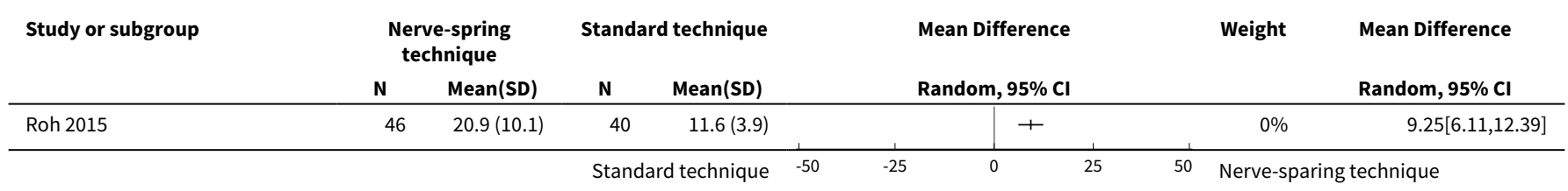

Analysis 7.2. Comparison 7 Flow rate ( $\mathrm{mL}$ per second), Outcome 2 Maximum flow rate ( $\mathrm{mL}$ per second) at 6-12 months after operation.

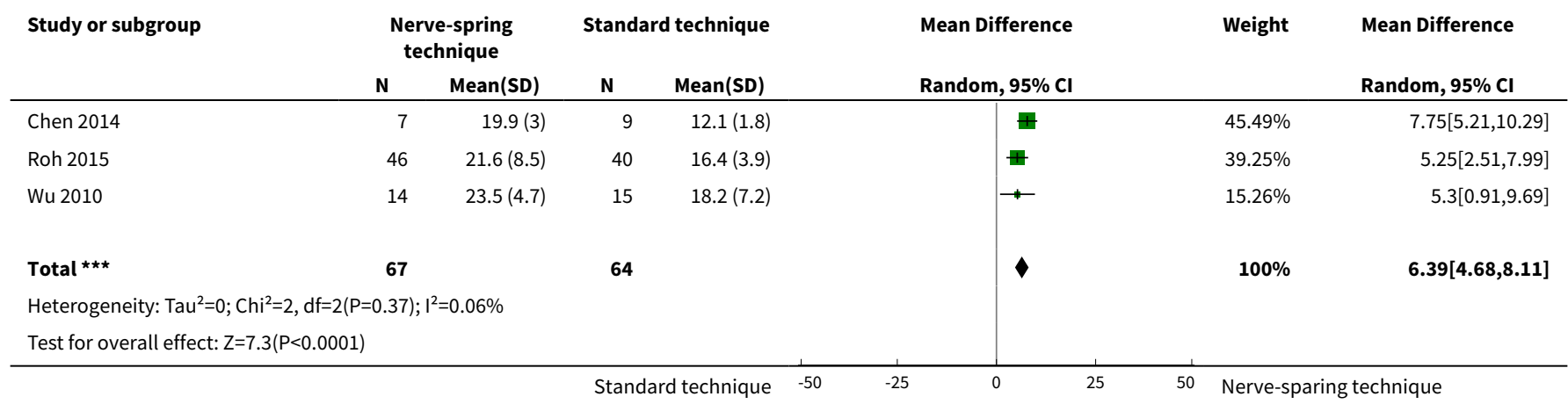

Nerve-sparing radical hysterectomy compared to standard radical hysterectomy for women with early stage cervical cancer (stage la2 to 36 Ila) (Review)

Copyright (c) 2019 The Cochrane Collaboration. Published by John Wiley \& Sons, Ltd. 
Comparison 8. Detrusor pressure $\left(\mathrm{cmH}_{2} \mathrm{O}\right)$

\begin{tabular}{lllll}
\hline Outcome or subgroup title & No. of studies & $\begin{array}{l}\text { No. of partici- } \\
\text { pants }\end{array}$ & Statistical method & Effect size \\
\hline $\begin{array}{l}\text { 1 Detrusor pressure at maximum flow at 1 } \\
\text { month after operation }\end{array}$ & 1 & & $\begin{array}{l}\text { Mean Difference (IV, Ran- } \\
\text { dom, 95\% Cl) }\end{array}$ & Subtotals only \\
\hline $\begin{array}{l}\text { 2 Detrusor pressure at maximum flow at } \\
\text { 6-12 months after operation }\end{array}$ & 2 & 102 & $\begin{array}{l}\text { Mean Difference (IV, Ran- } \\
\text { dom, 95\% Cl) }\end{array}$ & $9.49[0.83,18.16]$ \\
\hline
\end{tabular}

Analysis 8.1. Comparison 8 Detrusor pressure $\left(\mathrm{cmH}_{2} \mathrm{O}\right)$, Outcome 1 Detrusor pressure at maximum flow at 1 month after operation.

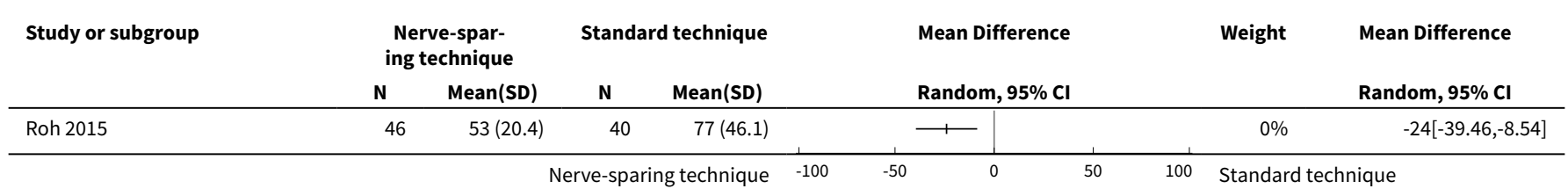

Analysis 8.2. Comparison 8 Detrusor pressure $\left(\mathrm{cmH}_{2} \mathrm{O}\right)$, Outcome 2 Detrusor pressure at maximum flow at 6-12 months after operation.

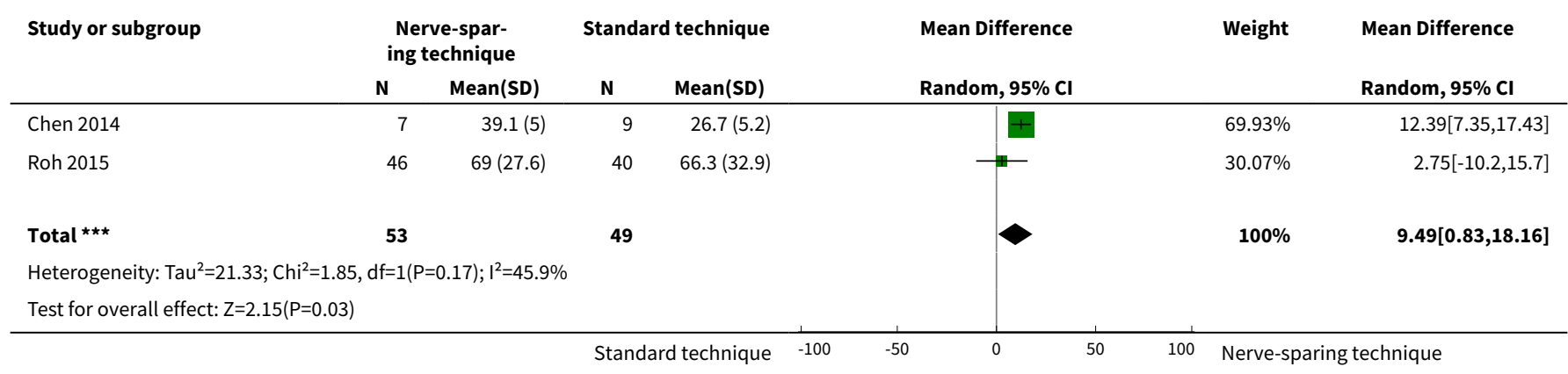

\section{Comparison 9. Operative time (minutes)}

\begin{tabular}{lllll}
\hline Outcome or subgroup title & No. of studies & $\begin{array}{l}\text { No. of partici- } \\
\text { pants }\end{array}$ & Statistical method & Effect size \\
\hline 1 Operative time $(\min )$ & 3 & 140 & $\begin{array}{l}\text { Mean Difference (IV, Random, 95\% } \\
\text { CI) }\end{array}$ & $11.57[-10.13,33.27]$ \\
\hline
\end{tabular}

Nerve-sparing radical hysterectomy compared to standard radical hysterectomy for women with early stage cervical cancer (stage la2 to 
Analysis 9.1. Comparison 9 Operative time (minutes), Outcome 1 Operative time ( $\mathrm{min})$.

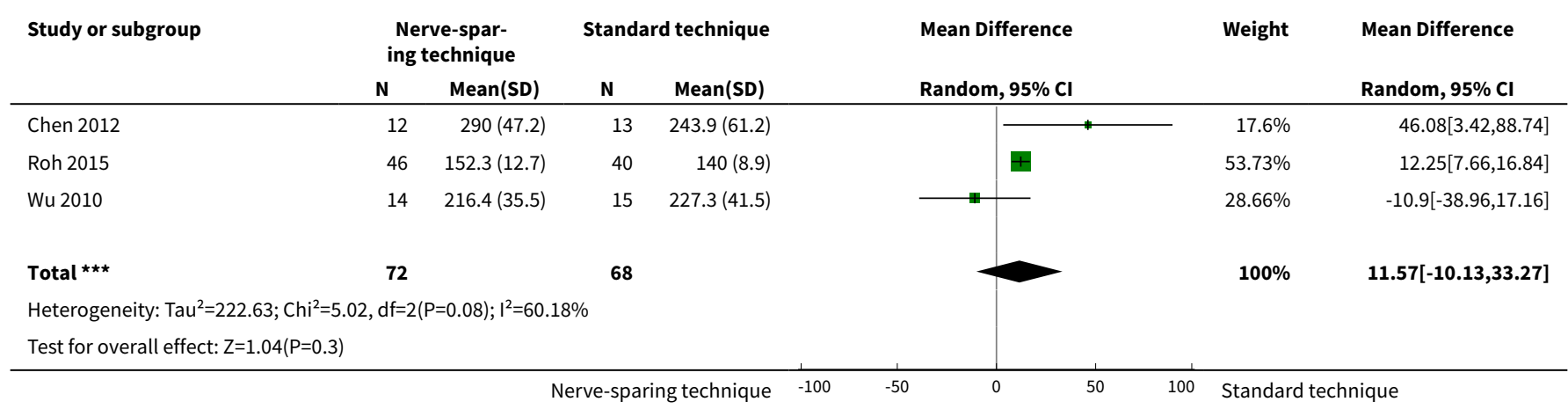

\section{Comparison 10. Estimated blood loss $(\mathrm{mL})$}

\begin{tabular}{lllll}
\hline Outcome or subgroup title & No. of studies & $\begin{array}{l}\text { No. of partici- } \\
\text { pants }\end{array}$ & Statistical method & Effect size \\
\hline 1 Estimated blood loss $(\mathrm{mL})$ & 3 & 140 & $\begin{array}{l}\text { Mean Difference (IV, Random, 95\% } \\
\text { Cl) }\end{array}$ & $\begin{array}{l}-36.89[-200.12, \\
126.35]\end{array}$ \\
\hline
\end{tabular}

Analysis 10.1. Comparison 10 Estimated blood loss (mL), Outcome 1 Estimated blood loss $(\mathrm{mL})$.

\begin{tabular}{|c|c|c|c|c|c|c|c|}
\hline \multirow{3}{*}{$\begin{array}{l}\text { Study or subgroup } \\
\text { Chen } 2012\end{array}$} & \multicolumn{2}{|c|}{$\begin{array}{l}\text { Nerve-spar- } \\
\text { ing technique }\end{array}$} & \multicolumn{2}{|c|}{ Standard technique } & \multirow{2}{*}{$\begin{array}{l}\text { Mean Difference } \\
\text { Random, 95\% Cl }\end{array}$} & \multirow[t]{2}{*}{ Weight } & \multirow{2}{*}{$\begin{array}{l}\text { Mean Difference } \\
\text { Random, } 95 \% \mathrm{Cl}\end{array}$} \\
\hline & $\mathbf{N}$ & $\operatorname{Mean}(S D)$ & $\mathbf{N}$ & Mean(SD) & & & \\
\hline & 12 & $\begin{array}{r}666.7 \\
(242.5)\end{array}$ & 13 & $\begin{array}{r}753.9 \\
(415.1)\end{array}$ & $\longrightarrow$ & $25.58 \%$ & $-87.18[-351.24,176.88]$ \\
\hline Roh 2015 & 40 & $\begin{array}{r}520.8 \\
(239.8)\end{array}$ & 46 & $\begin{array}{r}478.9 \\
(206.5)\end{array}$ & & $61.23 \%$ & $41.9[-53.41,137.21]$ \\
\hline Wu 2010 & 14 & $\begin{array}{r}571.4 \\
(504.1)\end{array}$ & 15 & $\begin{array}{r}876.7 \\
(618.4)\end{array}$ & - & $13.18 \%$ & $-305.24[-714.72,104.24]$ \\
\hline Total *** & 66 & & 74 & & & $100 \%$ & $-36.89[-200.12,126.35]$ \\
\hline \multicolumn{8}{|c|}{ Heterogeneity: $\mathrm{Tau}^{2}=8963.1 ; \mathrm{Chi}^{2}=3.23, \mathrm{df}=2(\mathrm{P}=0.2) ; \mathrm{I}^{2}=38 \%$} \\
\hline \multicolumn{8}{|c|}{ Test for overall effect: $Z=0.44(P=0.66)$} \\
\hline
\end{tabular}

\section{ADDITIONAL TABLES}

Table 1. Cancer recurrence

\begin{tabular}{|c|c|c|c|c|c|}
\hline \multirow[t]{2}{*}{ Study } & \multirow[t]{2}{*}{ Follow-up time } & \multicolumn{2}{|c|}{ Recurrence stratified by groups } & \multirow{2}{*}{$\begin{array}{l}\text { Sites of recur- } \\
\text { rence }\end{array}$} & \multirow{2}{*}{$\begin{array}{l}\text { Death from any caus- } \\
\text { es }\end{array}$} \\
\hline & & $\begin{array}{l}\text { Nerve-sparing } \\
\mathrm{RH}\end{array}$ & Standard RH & & \\
\hline Roh 2015 & $\begin{array}{l}\text { Median follow-up time of the entire } \\
\text { cohort: } 101 \text { months (range, } 13 \text { to } \\
137 \text { months) }\end{array}$ & $3 / 46(6.52 \%)$ & $2 / 40(5.0 \%)$ & Lung (2) & $\begin{array}{l}\text { one participant in } \\
\text { nerve-sparing group }\end{array}$ \\
\hline
\end{tabular}

Nerve-sparing radical hysterectomy compared to standard radical hysterectomy for women with early stage cervical cancer (stage la2 to 38 Ila) (Review)

Copyright $\odot 2019$ The Cochrane Collaboration. Published by John Wiley \& Sons, Ltd. 
Table 1. Cancer recurrence (Continued)

\begin{tabular}{|c|c|c|c|c|c|}
\hline & & & & $\begin{array}{l}\text { Lung and liver } \\
\text { (1) } \\
\text { Lung and pelvis } \\
\text { (1) } \\
\text { Para-aortic } \\
\text { node (1) }\end{array}$ & $\begin{array}{l}\text { had lung and liver } \\
\text { metastases }\end{array}$ \\
\hline Chen 2012 & $\begin{array}{l}\text { Median follow-up time nerve-spar- } \\
\text { ing RH group: } 33.5 \text { months (range, } \\
25 \text { to } 37 \text { months); median follow-up } \\
\text { time in standard RH group: } 34 \\
\text { months (range, } 27 \text { to } 37 \text { months) }\end{array}$ & $1 / 12(8.3 \%)$ & $0 / 13(0 \%)$ & $\begin{array}{l}\text { Sigmoid colon } \\
\text { (1) }\end{array}$ & $\begin{array}{l}\text { one participant in } \\
\text { nerve-sparing group } \\
\text { had colonic metasta- } \\
\text { sis }\end{array}$ \\
\hline
\end{tabular}

$\mathrm{RH}$, radical hysterectomy

Table 2. Perioperative complications

\begin{tabular}{|c|c|c|c|}
\hline Study & Complications & Nerve-sparing RH & Standard RH \\
\hline \multirow[t]{6}{*}{ Wu 2010} & Lymphocoele & $1 / 14(7.1 \%)$ & $2 / 15(13.3 \%)$ \\
\hline & Postoperative fever & $2 / 14(14.3 \%)$ & $4 / 15(26.7 \%)$ \\
\hline & Poor incision healing & $1 / 14(7.1 \%)$ & $2 / 15(13.3 \%)$ \\
\hline & Intestinal obstruction & $0 / 14(0 \%)$ & $0 / 15(0 \%)$ \\
\hline & Urinary tract injury & $0 / 14(0 \%)$ & $0 / 15(0 \%)$ \\
\hline & Deep vein thrombosis & $0 / 14(0 \%)$ & $0 / 15(0 \%)$ \\
\hline \multirow[t]{3}{*}{ Chen 2014} & Bladder injury & $0 / 30(0 \%)$ & $0 / 35(0 \%)$ \\
\hline & Fistula/ureter injury & $0 / 30(0 \%)$ & $0 / 35(0 \%)$ \\
\hline & Gastrointestinal injury & $0 / 30(0 \%)$ & $0 / 35(0 \%)$ \\
\hline \multirow[t]{2}{*}{ Roh 2015} & Incisional hernia & $1 / 46(2.2 \%)$ & $1 / 40(2.5 \%)$ \\
\hline & Infected lymphocoele & $1 / 46(2.2 \%)$ & $2 / 40(5.0 \%)$ \\
\hline
\end{tabular}

$\mathrm{RH}$, radical hysterectomy; Data are present as number of event divided by number of women evaluated

\section{A P PE N DICES}

\section{Appendix 1. The International Federation of Gynecology and Obstetrics (FIGO) staging for carcinoma of the cervix}

\begin{tabular}{|c|c|c|}
\hline FIGO Stage & Description & \\
\hline I & The carcinoma is confined to the cervix. & \\
\hline
\end{tabular}


IA
Invasive cancer identified only microscopically. (All gross lesions even with superficial invasion are Stage IB cancers.) Invasion is limited to measured stromal invasion with a maximum depth of $5 \mathrm{~mm}$ and no wider than $7 \mathrm{~mm}$.

\begin{tabular}{|c|c|c|c|}
\hline & & IA1 & $\begin{array}{l}\text { Measured invasion of stroma } \leq 3 \mathrm{~mm} \text { in depth and } \leq 7 \mathrm{~mm} \\
\text { width }\end{array}$ \\
\hline & & IA2 & $\begin{array}{l}\text { Measured invasion of stroma }>3 \mathrm{~mm} \text { and }<5 \mathrm{~mm} \text { in depth and } \leq \\
7 \mathrm{~mm} \text { width }\end{array}$ \\
\hline & \multicolumn{2}{|l|}{ IB } & $\begin{array}{l}\text { Clinical lesions confined to the cervix, or preclinical lesions } \\
\text { greater than stage IA }\end{array}$ \\
\hline & & IB1 & Clinical lesions no greater than $4 \mathrm{~cm}$ in size \\
\hline & & IB2 & Clinical lesions $>4 \mathrm{~cm}$ in size \\
\hline \multirow[t]{5}{*}{ II } & & & $\begin{array}{l}\text { The carcinoma extends beyond the uterus, but has not extend- } \\
\text { ed onto the pelvic wall or to the lower third of vagina. }\end{array}$ \\
\hline & \multicolumn{2}{|l|}{ IIA } & $\begin{array}{l}\text { Involvement of up to the upper two-thirds of the vagina. No ob- } \\
\text { vious parametrial involvement }\end{array}$ \\
\hline & & IIA1 & Clinically visible lesion $\leq 4 \mathrm{~cm}$ \\
\hline & & IIA2 & Clinically visible lesion $>4 \mathrm{~cm}$ \\
\hline & \multicolumn{2}{|l|}{ IIB } & Parametrial involvement, but not onto the pelvic sidewall \\
\hline \multirow[t]{3}{*}{ III } & & & $\begin{array}{l}\text { The carcinoma has extended onto the pelvic sidewall. On rectal } \\
\text { examination, there is no cancer free space between the tumour } \\
\text { and pelvic sidewall. The tumour involves the lower third of the } \\
\text { vagina. All cases of hydronephrosis or non-functioning kidney } \\
\text { should be included unless they are known to be due to other } \\
\text { causes. }\end{array}$ \\
\hline & \multicolumn{2}{|l|}{ IIIA } & $\begin{array}{l}\text { Involvement of the lower vagina but no extension onto pelvic } \\
\text { sidewall }\end{array}$ \\
\hline & \multicolumn{2}{|l|}{ IIIB } & $\begin{array}{l}\text { Extension onto the pelvic sidewall, or hydronephrosis/non- } \\
\text { functioning kidney }\end{array}$ \\
\hline \multirow[t]{3}{*}{ IV } & & & $\begin{array}{l}\text { The carcinoma has extended beyond the true pelvis or has clin- } \\
\text { ically involved the mucosa of the bladder and/or rectum. }\end{array}$ \\
\hline & IVA & & Spread to adjacent pelvic organs \\
\hline & IVB & & Spread to distant organs \\
\hline
\end{tabular}

\section{Appendix 2. Classifications of radical hysterectomy}


Piver-Rutledge-Smith

(Piver 1974)

\section{Extent of surgery}

\begin{tabular}{ll}
\hline Class I: & - Identification of ureters to avoid injury \\
extrafascial hysterecto- & - Uterine vessels are resected and ligated close to the uterine isthmus \\
my & - Uterosacral and cardinal ligaments are not removed \\
& - No vaginal portion is excised \\
\hline Class II: & - Ureters are dissected in the paracervical tissues but are not separated from the pubovesical ligament \\
modified radical hys- & - Uterosacral and cardinal ligaments are excised up to the medial half portions \\
terectomy (Wertheim) & - Vagina is excised up to the upper third level \\
& - Pelvic lymphadenectomy \\
\hline Class III: & - Complete dissection of ureters from the pubovesical ligament except for the small part where the um- \\
classical radical hys- & bilical bladder artery is located to the level of their penetration into the bladder \\
terectomy (Meigs) & Uterine arteries are cut off at the origin \\
& Uterosacral and cardinal ligaments are resected as close to sacral insertion and pelvic side wall, respec- \\
& Vagina is removed up to the upper half level \\
\hline
\end{tabular}

\begin{tabular}{ll}
\hline Class V & Class V differs from Class IV with the addition of the excision of a portion of the ureter or bladder which is \\
involved by the tumour
\end{tabular}

Querleu and Morrow

\section{Extent of surgery}

(Querleu 2008)

Type A: minimum resection of paracervix

(extrafascial hysterectomy)
- The position of ureters are determined by palpation or direct vision without freeing from their beds

- The paracervix is transected medial to the ureter but lateral to the cervix

- The uterosacral and vesicouterine ligaments are not transected at the distance from the uterus

- Vaginal resection is at a minimum, generally less than $10 \mathrm{~mm}$ without removal of the paracolpos
Type B: transection of paracervix at the ureter

\section{B1 \\ 1}

- Ureters are unroofed and dissected laterally, permitting transec-
tion of the paracervix at the level of the ureteral tunnel
The posterior and deep neural component of the paracevix caudal
to the deep uterine vein is not resected
- At least $10 \mathrm{~mm}$ of the vagina from the cervix or tumour is excised
- As described in B1 with additional removal of the lateral paracer-
vical lymph nodes
- Uterosacral ligament is transected at the sacral insertion
- Vesicouterine ligament is transected at the bladder
- Ureters are mobilised completely
Vagina is excised at least $15-20 \mathrm{~mm}$ from the tumour and the cor-
- WiTH the preservation of the autonomic nerves

Nerve-sparing radical hysterectomy compared to standard radical hysterectomy for women with early stage cervical cancer (stage la2 to 
(Continued)

$\mathrm{C2}$

D1

Type D: Laterally ex-

tended resection
- As described in C1 but WITHOUT the preservation of the autonomic nerves

- Resection of the entire paracervix at the pelvic side wall along with the hypogastric vessels, exposing the roots of the sciatic nerve

- Total resection of the vessels of the lateral part of the paracervix

- As described in D1 plus resection of the entire paracervix with the hypogastric vessels and adjacent fascia and muscles

\begin{tabular}{|c|c|}
\hline $\begin{array}{l}\text { GCG-EORTC a (Mota } \\
\text { 2008) }\end{array}$ & Extent of surgery \\
\hline Type I & Simple hysterectomy \\
\hline $\begin{array}{l}\text { Type II: modified radical } \\
\text { hysterectomy b }\end{array}$ & $\begin{array}{l}\text { - The uterus, paracervix and upper vagina }(10-20 \mathrm{~mm}) \text { are removed after dissection of the ureters to the } \\
\text { point of their entry to the bladder } \\
\text { - Uterine arteries are cut off and ligated } \\
\text { - Medial half of parametria and proximal uterosacral ligaments are transected }\end{array}$ \\
\hline $\begin{array}{l}\text { Type III: radical hys- } \\
\text { terectomy b }\end{array}$ & $\begin{array}{l}\text { - En bloc removal of the uterus with the upper third of the vagina along with the paracervical and par- } \\
\text { avaginal tissues } \\
\text { - Uterine arteries are cut off and ligated at their origin } \\
\text { - The entire width of the parametria is resected bilaterally } \\
\text { - The entire uterosacral ligament is resected }\end{array}$ \\
\hline
\end{tabular}

Type IV: extended radical hysterectomy $b$

- Differs from Type 3, as three-quarters of the vagina and paravaginal tissues are resected

Type V: partial exenter-

- Terminal ureters or segments of bladder or rectum are resected along with the uterus and parametria ationb

a Gynecological Cancer Group of the European Organization for Research and Treatment of Cancer

$\mathrm{b}$ in conjunction with a systematic bilateral pelvic lymphadenectomy

\section{Appendix 3. CENTRAL search strategy}

\#1. MeSH descriptor: [Uterine Cervical Neoplasms] this term only

\#2. ((cervi $\left.{ }^{\star}\right)$ near/5 (cancer ${ }^{\star}$ or tumor ${ }^{\star}$ or tumour ${ }^{\star}$ or neoplas ${ }^{\star}$ or carcinoma* or adenocarcinoma* or malignan $\left.{ }^{\star}\right)$ )

\#3. (\#1 or \#2)

\#4. MeSH descriptor: [Hysterectomy] explode all trees

\#5. hysterectom*

\#6. ((uter ${ }^{\star}$ or womb) near/5 (remov* or excis $\left.\left.{ }^{\star}\right)\right)$

\#7. (\#4 or \#5 or \#6)

\#8. MeSH descriptor: [Urinary Bladder] this term only

\#9. MeSH descriptor: [Urinary Catheterization] this term only

\#10. MeSH descriptor: [Urinary Bladder Diseases] explode all trees

\#11. MeSH descriptor: [Lower Urinary Tract Symptoms] explode all trees

\#12. MeSH descriptor: [Urination Disorders] explode all trees

\#13. MeSH descriptor: [Urinary Tract Infections] explode all trees

\#14. MeSH descriptor: [Urination] this term only

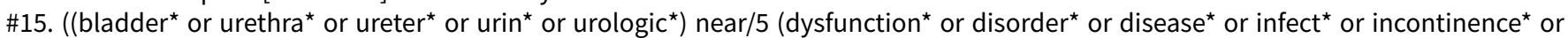
urgenc $^{\star}$ or injur ${ }^{\star}$ or damage $)$ )

\#16. (\#8 or \#9 or \#10 or \#11 or \#12 or \#13 or \#14 or \#15)

\#17. (\#3 and \#7 and \#16)

Nerve-sparing radical hysterectomy compared to standard radical hysterectomy for women with early stage cervical cancer (stage la2 to 


\section{Appendix 4. MEDLINE Ovid search strategy}

1. Uterine Cervical Neoplasms/

2. (cervi ${ }^{\star} \operatorname{adj5}$ (cancer ${ }^{\star}$ or tumor ${ }^{\star}$ or tumour ${ }^{\star}$ or neoplas ${ }^{\star}$ or carcinoma* or adenocarcinoma* or malignan $\left.{ }^{\star}\right)$ ).mp.

3. 1 or 2

4. exp Hysterectomy/

5. hysterectom*.mp.

6. ((uter ${ }^{\star}$ or womb) adj5 (remov* or excis $\left.\left.{ }^{\star}\right)\right)$.mp.

7. 4 or 5 or 6

8. Urinary Bladder/

9. Urinary Catheterization/

10. exp Urinary Bladder Diseases/

11. exp Lower Urinary Tract Symptoms/

12. exp Urination Disorders/

13. exp Urinary Tract Infections/

14. Urination/

15. ((bladder ${ }^{\star}$ or urethra* or ureter $^{\star}$ or urin ${ }^{\star}$ or urologic $\left.{ }^{\star}\right)$ adj5 (dysfunction* or disorder $^{\star}$ or disease or infect $^{\star}$ or incontinence* or urgenc $^{\star}$ or injur ${ }^{\star}$ or damage*)).mp.

16.8 or 9 or 10 or 11 or 12 or 13 or 14 or 15

17.3 and 7 and 16

key: $\mathrm{mp}=$ title, abstract, subject headings, heading word, drug trade name, original title, device manufacturer, drug manufacturer name

\section{Appendix 5. Embase Ovid search strategy}

1. uterine cervix tumor/

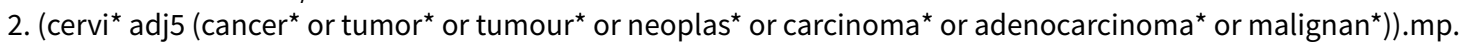

3. 1 or 2

4. exp hysterectomy/

5. hysterectom ${ }^{\star} . \mathrm{mp}$.

6. ((uter ${ }^{\star}$ or womb) adj5 (remov* or excis $\left.\left.{ }^{\star}\right)\right) \cdot \mathrm{mp}$.

7.4 or 5 or 6

8. bladder/

9. bladder catheterization/

10. exp bladder disease/

11. exp lower urinary tract symptom/

12. exp micturition disorder/

13. exp urinary tract infection/

14. micturition/

15. ((bladder ${ }^{\star}$ or urethra ${ }^{\star}$ or ureter ${ }^{\star}$ or urin ${ }^{\star}$ or urologic $\left.{ }^{\star}\right)$ adj5 (dysfunction ${ }^{\star}$ or disorder ${ }^{\star}$ or disease or infect $^{\star}$ or incontinence* or urgenc $^{\star}$ or injur ${ }^{\star}$ or damage $)$ ).mp.

16.8 or 9 or 10 or 11 or 12 or 13 or 14 or 15

17. 3 and 7 and 16

key: $\mathrm{mp}=$ title, abstract, subject headings, heading word, drug trade name, original title, device manufacturer, drug manufacturer name

\section{Appendix 6. 'Risk of bias' assessment}

'Risk of bias' assessment based on Chapter 8 of Higgins 2011:

- Random sequence generation

- Low risk of bias, e.g. participants assigned to treatments on the basis of a computer-generated random sequence or a table of random numbers.

- High risk of bias, e.g. participants assigned to treatments on the basis of date of birth, clinic ID number or surname, or no attempt to randomise participants.

- Unclear risk of bias, e.g. not reported, information not available.

- Allocation concealment

- Low risk of bias, e.g. where the allocation sequence could not be foretold.

- High risk of bias, e.g. allocation sequence could be foretold by patients, investigators or treatment providers.

- Unclear risk of bias, e.g. not reported.

- Blinding of participants and personnel

- Low risk of bias if participants and personnel were adequately blinded.

- High risk of bias if participants were not blinded to the intervention that the participant received.

Nerve-sparing radical hysterectomy compared to standard radical hysterectomy for women with early stage cervical cancer (stage la2 to 
- Unclear risk of bias if this was not reported or unclear.

- Blinding of outcomes assessors

- Low risk of bias if outcome assessors were adequately blinded.

- High risk of bias if outcome assessors were not blinded to the intervention that the participant received.

- Unclear risk of bias if this was not reported or is unclear.

- Incomplete outcome data: we will record the proportion of participants whose outcomes were not reported at the end of the study. We will code a satisfactory level of loss to follow-up for each outcome as:

- Low risk of bias, e.g. if fewer than $20 \%$ of participants were lost to follow-up and reasons for loss to follow-up were similar in both treatment arms

- High risk of bias, e.g. if more than $20 \%$ of participants were lost to follow-up or reasons for loss to follow-up differed between treatment arms.

- Unclear risk of bias, e.g. if loss to follow-up was not reported.

- Selective reporting of outcomes

- Low risk of bias, e.g. review reports all outcomes specified in the protocol.

- High risk of bias, e.g. it is suspected that outcomes have been selectively reported in the study.

- Unclear risk of bias, e.g. it is unclear whether outcomes have been selectively reported.

- Other bias

- Low risk of bias, e.g. the review authors do not suspect any other source of bias and the trial appears to be methodologically sound.

- High risk of bias, e.g. the review authors suspect that the trial was prone to an additional bias.

- Unclear risk of bias, e.g. the review authors are uncertain whether an additional bias may have been present.

\section{CONTRIBUTIONS OF AUTHORS}

Chumnan Kietpeerakool (CK): conceived the review question, developed, coordinated and completed the review Apiwat Aue-aungkul (AA): conceived the review question, developed, and completed the review Khadra Galaal (KG): performed part of the editing of the protocol and advised on part of the review Chetta Ngamjarus (CN): performed part of the editing of the protocol and advised on part of the review Pisake Lumbiganon $(\mathrm{PL})$ : coordinated the development of the protocol, edited the protocol and advised on the review

\section{DECLARATIONS OF INTEREST}

CK: nothing to declare AA: nothing to declare KG: nothing to declare $\mathrm{CN}$ : nothing to declare PL: nothing to declare

\section{SOURCES OF SUPPORT}

\section{Internal sources}

- Department of Obstetrics and Gynaecology, Faculty of Medicine, Khon Kaen University, Thailand.

- Gynaecological Oncology, Princess Alexandra Wing, Royal Cornwall Hospital, Truro, UK.

- Department of Epidemiology and Biostatistics, Faculty of Public Health, Khon Kaen University, Thailand.

- Cochrane Thailand, Thailand.

\section{External sources}

- Thailand Research Fund (Distinguished Professor Award), Thailand.

- Long-term institutional development HUBs (LID-HUBs), the Human Reproduction Programme (HRP) Alliance for Research Capacity Strengthening, World Health Organization, Switzerland.

\section{DIFFERENCES BETWEEN PROTOCOL AND REVIEW}

\section{Types of outcome measures}

In an attempts to cover a broad range of outcome measures for bladder functions following radical hysterectomy, we added 'time to postvoid residual volume of urine 12 months after operation' as a one of the secondary outcomes.

In the review protocol, we stated that we would categorise the severity of the following adverse events according to the Common Terminology Criteria for Adverse Events (CTCAE 2010). However, it was not feasible to comply with this plan as none of the included studies

Nerve-sparing radical hysterectomy compared to standard radical hysterectomy for women with early stage cervical cancer (stage la2 to 44 IIa) (Review)

Copyright (c) 2019 The Cochrane Collaboration. Published by John Wiley \& Sons, Ltd. 
reported the severity of adverse events in detail (See Table 2 for the types of perioperative complications reported among the included studies).

\section{Data extraction and management}

We additionally stated that "If continuous outcomes were expressed as median and range, we planned to contact the study author to obtain sample mean and SD. If this is not possible, we planned to convert this data using the formula suggested by Wan 2014".

\section{Measures of treatment effect}

In the review protocol, we stated that we would measure the time to postvoid residual volume of urine $\leq 50 \mathrm{~mL}$ as a time-to-event outcomes. However, it was not possible to estimate the HRs of this outcome using the information reported. So, we estimated the treatment effects of intervention on the time to postvoid residual volume of urine using mean difference with a $95 \% \mathrm{Cl}$.

\section{Assessment of reporting biases}

As there were only four trials that met our inclusion criteria, we were unable to construct funnel plots to determine the possibility of publication bias as previously stated in the review protocol. In a future update of this review, we will examine funnel plots corresponding to meta-analysis of the primary outcome to assess the potential for small study effects, such as publication bias, if we are able to identify more than 10 studies. We will assess funnel plot asymmetry visually (Sterne 2011).

\section{Subgroup analysis and investigation of heterogeneity}

As there were few trials (assessing 205 women) that met our inclusion criteria, subgroup analyses according to stage of the disease (la2Ib1 versus Ib2 or higher stages), and degree of lymph node dissection (pelvic versus pelvic and para-aortic), as mentioned in the review protocol, were not feasible. However, we considered these factors in the interpretation of review findings. In future updates, we will perform subgroup analysis according to these factors, if feasible.

\section{Sensitivity analysis}

We performed No sensitivity analysis was performed, as all data were obtained from published RCTs containing only women with cervical cancer stage la2 to Ila and all included RCTs were at unclear risk of bias for allocation concealment.

\section{IN DEX TERMS}

\section{Medical Subject Headings (MeSH)}

*Autonomic Nervous System; Disease-Free Survival; Hysterectomy [adverse effects] [ ${ }^{\star}$ methods]; Neoplasm Recurrence, Local; Neoplasm Staging; Organ Sparing Treatments [adverse effects] [ ${ }^{*}$ methods] [mortality]; Pelvis [innervation]; Postoperative Complications [ ${ }^{\star}$ prevention \& control]; Randomized Controlled Trials as Topic; Urinary Bladder [*innervation]; Urination Disorders [etiology] [ ${ }^{\star}$ prevention \& control]; Uterine Cervical Neoplasms [pathology] [ ${ }^{\star}$ surgery]

\section{MeSH check words}

Female; Humans 